\title{
Una aproximación a la estructura productiva de Entre Ríos en la década de 1930
}

\section{An approximation to the productive structure of Entre Rios in the 1930}

\author{
José Antonio Mateo \\ Doctor en Historia de la Universitat Pompeu Fabra \\ Profesor de la Universidad Nacional de Mar del Plata, Argentina \\ https://orcid.org/0000-0001-6599-5684 \\ jamateo@fceco.uner.edu.ar
}

\section{Maximiliano Camarda}

Doctor en Historia de la Universidad Nacional de la Plata, Argentina Profesor de la Universidad Nacional de Entre Ríos, Argentina https://orcid.org/0000-0002-6196-4757 maximilianocamarda@hotmail.com

\author{
Leandro Rodríguez \\ Contador Público y Doctorando en Ciencias Sociales \\ de la Universidad Nacional de Entre Ríos \\ Secretario de investigación de la Facultad de Ciencias Económicas \\ de la Universidad Nacional de Entre Ríos, Argentina \\ leandrorodriguez@fceco.uner.edu.ar
}

Fecha de recepción: 9 de noviembre del 2017

Fecha de aceptación: 23 de mayo de 12018

Disponible en línea: 27 de junio del 2018

Sugerencia de citación: Mateo, J.A., Camarda, M. y Rodríguez, L. (2018), Una aproximación a la estructura productiva de Entre Ríos en la década de 1930. tiempo\&economía, 5(2), 179-208, doi: http://dx.doi.org/10.21789/24222704.1251

\section{RESUMEN}

La depresión económica de los años treinta afectó con particular virulencia el agro de la pampa argentina. Para esa época el gobierno realizó el Censo Agropecuario Nacional en 1937. Este trabajo es una exploración de la estructura productiva de la provincia de Entre Ríos y sus 
formas de comercialización a partir del censo como fuente principal. Con ese fin se profundizará en los tamaños de las unidades productivas de cada uno de los departamentos, la mayoría de las producciones y la distancia a los puertos ferrovías y caminos de salida. Finalmente se cruzará esa información con la dinámica comercial de los puertos entrerrianos.

Palabras clave: Entre Ríos, estructura productiva, Censo agropecuario 1937, circulación de mercancías, Argentina, historia económica

Códigos JEL: N16, O13, R11, R40

\section{ABSTRACT}

The decade of 1930 was marked by the economic depression that affected with particular virulence the Pampas agricultural. In this context, the conservatives that intervened the government developed the National Agricultural Census in 1937. This work is an exploration of the productive structure of Entre Ríos and its forms of commercialization based on the use of the census as the main source. To this end, the sizes of the productive units of each of the departments, the majority of the productions and their distance to the rail ports and exit roads will be studied in depth. Finally, this information will be crossed with the commercial dynamics of the ports of Entre Ríos. In sum, this work will seek to obtain a detailed image of agricultural production with the aim of problematizing about the consequences of the 1930 crisis in this territory.

Keywords: Entre Ríos, productive structure, Agricultural census 1937, movement of goods, Argentina, economic history

JEL Codes: N16, O13, R11, R40 


\section{Introducción}

La década de 1930 estuvo marcada por la depresión económica que afectó con particular virulencia el agro pampeano. En este contexto, conservadores que intervinieron el gobierno desarrollaron cinco grandes censos: el Censo Nacional de Desocupados en 1932, el Censo Industrial en 1935, el Censo del Ministerio de Hacienda y el Hipotecario Nacional en 1936, y el Censo Agropecuario Nacional en 1937. Este último censo estuvo dirigido por la Dirección de Economía Rural y Estadística (DERE), dependiente del Ministerio de Agricultura y de la Dirección General de Estadística de la Nación del Ministerio de Hacienda. Además, contó con la participación de un gran número de asociaciones, cámaras, centros, confederaciones y cooperativas (González, 2014). Este trabajo es una primera exploración de la estructura productiva de Entre Ríos y sus formas de comercialización a partir de la utilización del censo como fuente principal. Con ese fin se profundizará en los tamaños de las unidades productivas de cada uno de los departamentos, la mayoría de las producciones y la distancia de las mismas a los puertos ferrovías y caminos de salida. En suma, en este trabajo se buscará obtener una imagen detallada de la producción agropecuaria con el objetivo de problematizar sobre las consecuencias de la crisis de 1930 en este territorio y establecer la proximidad del proceso con el contexto nacional.

Tomaremos el censo de 1937 como fuente principal para el análisis porque interpretamos que por la densidad informativa que contiene es un óptimo punto de partida para analizar la estructura económica entrerriana. No hallamos trabajos recientes vinculados al análisis de la estructura entrerriana con los cuales dialogar, lo que encontramos son investigaciones realizadas por actores del periodo (Reula, 1971) y trabajos que buscan profundizar en algunos aspectos específicos del período (Mathieu et al., 2017 y Biasizo, 2015).

\section{La provincia de Entre Ríos}

La provincia de Entre Ríos, junto a las de Corrientes y Misiones, conforman la llamada "Mesopotamia argentina", una región con características insulares dentro del territorio, enmarcada al oeste por el Río Paraná y al este por el Río Uruguay. Entre Ríos presenta una cualidad similar dentro de la Mesopotamia ya que sus límites también son hídricos. Los ríos Mocoretá y Gayquiraró unidos por el arroyo Las Tunas son su límite norte con la provincia de Corrientes, el Río Paraná el límite oeste con las provincias de Santa Fe y Buenos Aires, y el río Uruguay constituye su frontera con la República Oriental del Uruguay. La confluencia de aquellos dos grandes ríos constituye su límite sur conformado por una formación deltaica.

El relieve de la provincia es llano y surcado por una extensa red hidrográfica. Esta llanura es alterada por suaves ondulaciones o lomadas que impropiamente se denominan "cuchillas" (ya que su origen no es geológico-rocoso como en las cercanas de la República Oriental del Uruguay, sino de elevaciones fosilizados). Estás "cuchillas" son la Grande (que se extiende al este de norte a sur) y la de Montiel (que corre al oeste de noroeste a sureste). Por el valle entre las cuchillas circula de norte a sur el río Gualeguay que divide en dos a la provincia. Paralelos a este río, en dos líneas de falla, corren el arroyo Nogoyá al oeste y el río Gualeguaychú al este que dividen en cuatro espacios la parte meridional de la provincia. El arroyo Feliciano al oeste de la cuchilla de Montiel y el primer tramo del río Gualeguay, con sus afluentes, bañan la parte septentrional de la Provincia. 
La provincia de Entre Ríos presenta rasgos atípicos desde su proceso de poblamiento coIonial. La corona española aplicó en el territorio un proceso de colonización urbana que consistió en la fundación de ciudades que poco a poco fueron imponiendo y extendiendo su dominio político, económico y su influencia social sobre las zonas circundantes. Como consecuencia de este proceso se fundaron en el país 13 ciudades en el curso de sólo 41 años, cuya trascendencia las constituyó en capitales de trece de las catorce provincias argentinas originales. La provincia de Entre Ríos en cambio no se pobló alrededor de una de las 13 "ciudades territoriales" fundadas por los españoles.

La ciudad de Paraná tuvo un origen singular. El nacimiento del futuro centro urbano se produjo lenta e imperceptiblemente. Los primeros pobladores "blancos" del pago de la Brocada -como se denominó primitivamente a la región- fueron estableciéndose desde fines del siglo XVI, cuando Juan de Garay, luego de fundar Santa Fe, cruzó el río y otorgó a sus compañeros de empresa, y a sí mismo, extensiones de tierra abarcando las que luego serían los departamentos Paraná y La Paz. Pero fue a partir del traslado de la ciudad de Santa Fe (de cuyas autoridades dependía) a su sitio actual, en la segunda mitad del siglo xvII, que se desarrolló una firme corriente pobladora de la provincia.

En 1782, comisionado por el Virrey Vértiz, el Ayudante Mayor Tomás de Rocamora se trasladó a Paraná con el fin de erigir el caserío en villa (es decir dotarla de cabildo y autoridades), pero en cambio optó por institucionalizar otras tres villas: las de Gualeguay, Gualeguaychú y Concepción del Uruguay (Román, 2016). A principios del siglo xIX se desarrollaron alrededor de capellanías ${ }^{1}$ las localidades Tala, Villaguay y Victoria. Correspondió a la Asamblea General Constituyente del año 1813 erigir al caserío de la Bajada del Paraná en la Villa de Nuestra Señora del Rosario del Paraná, mientras que la urbanización planificada por el gobierno provincial desde 1831 dio lugar al nacimiento de Concordia, Diamante, La Paz, Federación y Colón. Quedaban así constituidos los departamentos existentes en el período estudiado.

\section{Colonización y evolución poblacional de Entre Ríos}

La derrota y dominación de los aborígenes charrúas en 1749 y la relativa paz al interior de la provincia en el período de las guerras civiles vivido en el país luego de la independencia, fueron factores que permitieron un temprano poblamiento rural. Durante la gobernación de Pascual Echagüe (1832-1841) y de Justo José de Urquiza (1841-1854) se dictaron normas que contribuyeron al poblamiento rural. Se legalizaron dominios y se realizaron concesiones de estancias, así como la venta de establecimientos que permitieron la instalación de industrias a vapor para productos derivados de la ganadería (saladeros, producción de grasa de yeguarizos y de lana). Sobre el final del período se proveyó de semillas para la diversificación de cultivos (básicamente cereales y frutales) y hubo una política de creación de huertas en escuelas de campaña para incentivar el trabajo rural. A esta época corresponde el surgimiento de los centros urbanos Villaguay, Diamante -con un puerto para la exportación- y La Paz (Arce, 1979).

1 Obras pías instauradas en la Iglesia Católica, mediante las cuales el fundador, generalmente una persona acaudalada, dejaba en su testamento una cantidad de dinero que se ponía en renta, para que con las ganancias se pagara la realización de un número determinado de misas por la salvación de su alma. 
Mapa 1. Departamentos de Entre Ríos en 1930, en azul Costa del Paraná, en rojo Departamentos Centrales y en blanco Costa del Uruguay

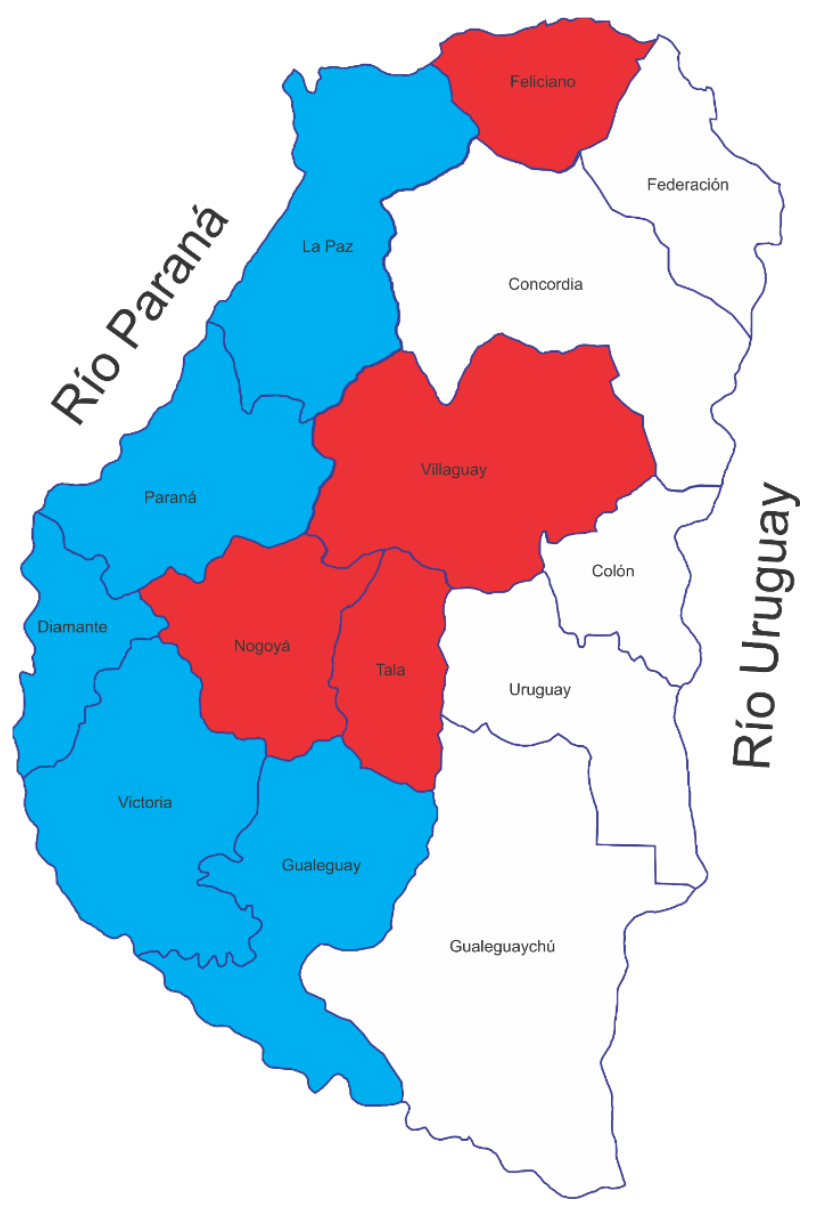

Los sucesos históricos que en la década de 1850 convirtieron a Paraná en la capital provisoria de la Confederación Argentina generaron un importante aporte de población a la ciudad. El apoyo de Urquiza a la colonización agrícola atrajo a numerosos agricultores y artesanos europeos (inmigrantes rusos, suizos, alemanes, franceses e italianos). También a migrantes internos debido a los conflictos en las provincias vecinas y en el Uruguay. Durante su gestión como presidente de la Confederación Argentina se fundaron las primeras colonias: la Colonia Agrícola Militar Las Conchas, al norte de Paraná (1853); la Colonia San José, en el departamento Colón (1857), integrada por suizos y, en menor, medida franceses e italianos. Con posterioridad, como desprendimiento de la Colonia San José, surgieron las colonias Hughes, $1^{\circ}$ de Mayo, La Suiza, Vázquez, 3 de febrero, Paso Paysandú, Arroyo Urquiza, La Matilde y Pantanoso.

El proceso inmigratorio cobró mayor impulso luego de la promulgación en 1876 de la Ley Avellaneda (817/76) de inmigración y colonización, cuyo origen eran Santa Fe. A principios de 1878 inmigrantes ruso-alemanes fundaron Colonia Alvear en el departamento Diamante y en 1879 Aldea Brasilera en el de Paraná. Nuevos contingentes de estas nacionalidades poblaron el mencionado departamento en las Aldeas Protestante, Spatzenkutter, Valle María y en el departamento Paraná se instalaron en las Aldeas María Luisa, San Juan y San Rafael. 
Ante la persecución a los judíos en Rusia durante el periodo 1892-1940 la Jewish Colonization Association -institución colonizadora creada por el barón Moritz von Hirsch en 1891compró alrededor de 3.000 leguas (unas 1.500 hectáreas) y formó una red de colonias posibilitando la radicación de inmigrantes judíos a lo largo de la principal línea férrea: primero en los departamentos Villaguay, Uruguay, Colón y Concordia y después de 1920 en La Paz y Paraná. Así nacieron las colonias Clara, San Antonio, Lucienville (conjunto del corredor central), López y Berro, Curbelo y Walter Moss, Santa Isabel, Palma Yatay (conjunto del corredor centro-noreste) y Louis Oungre, Leonard Cohen y Avigdor (conjunto del corredor noroeste). Hacia 1904 existían en la provincia 165 colonias rurales y en 1907 se contabilizaban 389. Sin embargo, la provincia también recibió inmigrantes de origen italiano y español, quienes, sin formar parte de la mencionada colonización agrícola, poblaron el sur provincial en el Departamento Gualeguaychú (Garcia y Mingo de Bevilacqua, 1998, p. 13).

La provincia de Entre Ríos ha tenido un comportamiento demográfico singular dentro de la región denominada "zona núcleo" agro ganadera de la Argentina. Desde el primer censo nacional hasta el último, su participación porcentual en la cuantía de efectivos poblacionales no ha dejado de caer, para ubicarse apenas por encima del 3\% de la población nacional en el censo de 2010, cuando en los dos primeros censos nacionales más que duplicaba esa proporción (Indec, 2010). Su población al momento del censo, proyectando los valores censales de 1914 y 1947 puede estimarse en 653.345 personas a una tasa de crecimiento porcentual anual del $1,18 \%$, por debajo de la nacional de $2,15 \%$.

Tabla 1. Evolución de la población en Entre Ríos y en Argentina, censos de 1869 a 1947

\begin{tabular}{|c|c|c|c|c|c|c|c|}
\hline $\begin{array}{l}\text { Año } \\
\text { censal }\end{array}$ & Entre Ríos & Argentina & $\begin{array}{l}\% \text { Entre } \\
\text { Ríos del } \\
\text { total }\end{array}$ & $\begin{array}{l}\text { Crecimiento } \\
\text { absoluto entre } \\
\text { censos Entre Ríos }\end{array}$ & $\begin{array}{c}\text { Crecimiento } \\
\text { relativo entre } \\
\text { censos Entre Ríos } \\
\% \\
\end{array}$ & $\begin{array}{c}r \\
\text { nacional } \\
\%\end{array}$ & $\begin{array}{c}r \\
\text { Entre Ríos } \\
\%\end{array}$ \\
\hline 1869 & 134.271 & 1.877 .490 & 7,2 & & & & \\
\hline 1895 & 292.019 & 4.044 .911 & 7,2 & 157.748 & 117,5 & 3,00 & 3,03 \\
\hline 1914 & 425.373 & 7.903 .662 & 5,4 & 133.354 & 45,7 & 3,59 & 2,00 \\
\hline 1947 & 787.362 & 15.893 .827 & 5,0 & 361.989 & 85,1 & 2,14 & 1,88 \\
\hline
\end{tabular}

$r=$ tasa de crecimiento porcentual anual.

Fuente: elaboración propia

Como puede observarse en la Tabla 1, en los tres primeros intervalos censales la población de la provincia, al margen de la irregularidad temporal que separó las compulsas de registro de población, se multiplicó a sí misma por seis en un proceso casi secular (1869-1947), mientras el país lo hizo por más de ocho. Las tasas de crecimiento porcentual anual ( $r$ ), aunque con fluctuaciones, tampoco se distanciaron mucho en ambas regiones, nacional y provincial, entre 1869 y 1947 . En efecto, el total del país creció a un $2,78 \%$ anual y la provincia de Entre Ríos a un $2,29 \%$, es decir con altas tasas en ambos distritos. 
Gráfica 1. Pirámide de población interpolada hacia 1935 a partir de los censos nacionales de 1914 y 1947

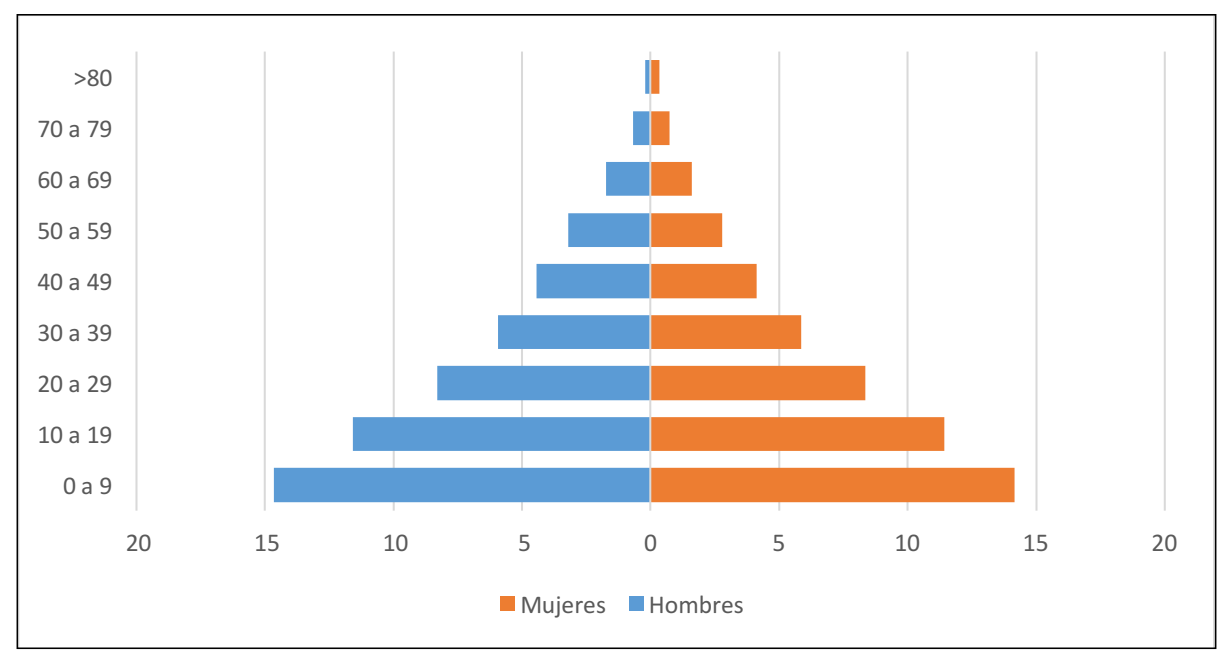

Fuente: elaboración propia

Interpolando los datos de grupos de edades entre los años censales vemos una merma de población entre los hombres mayores de 20 años y menores de 50 generando una relación de masculinidad casi equivalente en ese rango de población, acentuando un comportamiento que venía ocurriendo y es observable desde el censo de 1895. También se acentuó el progresivo proceso de des-ruralización, pasando de una relación de población urbana/rural en 1914 de $36,8 / 61,4 \%$ a $50,3 / 49,7$ en 1940 .

Gráfica 2. Relación entre población urbana y rural en Entre Ríos en 1935

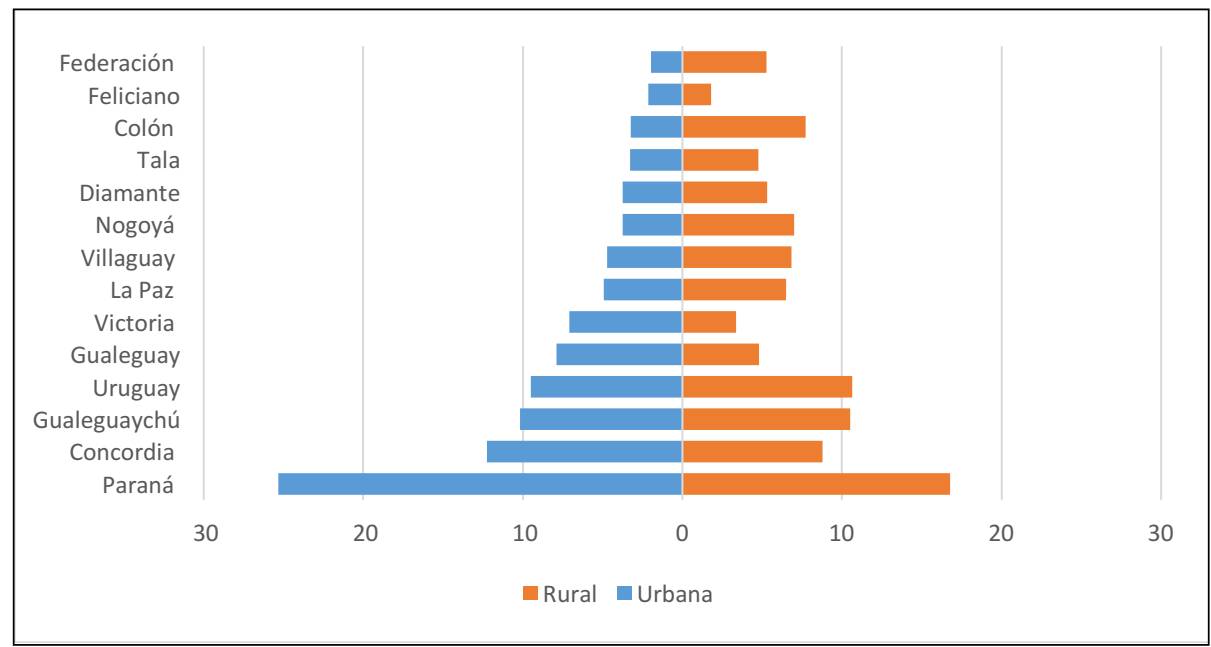

Fuente: elaboración propia. Datos interpolados de los censos de 1914 y 1947

El despoblamiento parece haber sido más acentuado en los departamentos centrales de Feliciano, Villaguay, Rosario del Tala y Nogoyá que entre 1914 y 1947 perdieron el 0,6\% de su 
población proporcional a manos de los departamentos de la costa del Paraná y del Uruguay que se incrementaron 0,30\% cada uno, es decir la merma repartida. Lattes (1974) estimó los movimientos migratorios internos en Argentina; citamos un fragmento de sus cálculos en la tabla 2.

Tabla 2. Proporción de inmigrantes y emigrantes por provincias, fechas censales, en porcentaje

\begin{tabular}{|c|c|c|c|c|}
\hline \multirow{2}{*}{ Provincia } & \multicolumn{2}{|c|}{1914} & \multicolumn{2}{c|}{1947} \\
\cline { 2 - 5 } & Inmigrantes & Emigrantes & Inmigrantes & Emigrantes \\
\hline Entre Ríos & 4,5 & 12,3 & 5,3 & 21,7 \\
\hline Capital Federal y Gran Buenos Aires & 5,5 & 5,0 & 13,4 & 4,9 \\
\hline Santa Fe & 21,3 & 16,1 & 17,7 & 18,7 \\
\hline
\end{tabular}

Fuente: Lattes (1974, p. 102)

Podemos apreciar una caída de la inmigración ya en 1895 que había pasado de 14,2\% en 1869 a 5,3\% en ese censo. Los porcentajes de inmigración se mantuvieron entre un 4 o 5\% hasta 1970. La emigración por su parte casi se duplicó ente 1914 y 1947. En Capital Federal y Gran Buenos Aires ocurrió lo contrario, y lo que se duplicó fue inmigración. Por su parte Santa Fe, que fuera un destino secundario de los emigrados entrerrianos seducidos por los aglomerados industriales edificados en torno a Rosario, si bien también tuvo altas tasas de emigración también fueron de inmigración, produciéndose en esa provincia el efecto colectivo o puerta giratoria, donde su población ingresaba y egresaba simultáneamente.

Hacia 1930 Entre Ríos se encontraba ya en proceso temprano de transición demográfica (Miro, 2000), con una tasa bruta de natalidad en torno al 35\% y una tasa bruta de mortalidad en el orden de un 14\%o con leve descenso hacia 1940 (Garcia \& Mingo de Bevilacqua, 1998, p. 20). Esto puede explicar que la base de la pirámide haya sido proporcionalmente más ancha que el nivel nacional. Si acompañó el proceso de envejecimiento por la cúspide con valores similares al total nacional de población mayor de 65 años.

Tabla 3. Indicadores de dependencia potencial en Argentina y en Entre Ríos según los censos de 1869 a 1947, en porcentaje

\begin{tabular}{|c|c|c|c|c|c|}
\hline \multirow{4}{*}{ Entre Ríos } & Grupos de edades & $\mathbf{1 8 6 9}$ & $\mathbf{1 8 9 5}$ & $\mathbf{1 9 1 4}$ & $\mathbf{1 9 4 7}$ \\
\cline { 2 - 6 } & 0 a 14 & 44,1 & 44,2 & 42,6 & 40,0 \\
\cline { 2 - 6 } & 15 a 64 & 53,5 & 53,7 & 54,7 & 56,4 \\
\cline { 2 - 6 } & $>65$ & 2,4 & 2,1 & 2,7 & 3,6 \\
\hline \multirow{3}{*}{ Argentina } & 0 a 14 & 41,3 & 41,3 & 40,1 & 30,9 \\
\cline { 2 - 6 } & 15 a 64 & 56,2 & 56,6 & 57,6 & 65,2 \\
\cline { 2 - 6 } & $>65$ & 2,5 & 2,1 & 2,3 & 3,9 \\
\hline
\end{tabular}

Fuente: elaboración propia

La combinación de estos indicadores hace que el índice de dependencia potencial (es decir, la relación entre la población potencialmente activa y los que en teoría dependen de ella) 
hizo que mientras a nivel nacional descendiera del 73,5\% en 1914 al 53,3\% en 1947, en la provincia lo hiciera solo del $82,8 \%$ al $77,3 \%$, manteniendo un alto grado de dependencia durante los críticos años de 1930.

\section{La situación política y económica de Entre Ríos en los años 1930}

El derrocamiento del presidente Yrigoyen en septiembre de 1930 y el inicio de una etapa signada por la proscripción política y el fraude electoral a nivel nacional, no alteraron la "normalidad" institucional en la provincia de Entre Ríos. El entonces gobernador en ejercicio, Eduardo Laurencena, opositor al personalismo, logró concluir su mandato sin sobresaltos en el mismo año del golpe, cediendo el poder en octubre de 1930 al gobernador electo unos meses antes, Herminio Quiróz, también radical antipersonalista. Sin embargo, esta última gestión duró muy poco. En mayo de 1931 falleció el vicegobernador Cándido Uranga y unos meses después murió el propio Quiróz. La acefalía del ejecutivo llevó a constituir un gobierno provisional y a convocar a elecciones.

En los comicios de noviembre de 1931 triunfó holgadamente la fórmula Etchevehere-Texier, consolidando el predominio del radicalismo antipersonalista. Luis Etchevehere, anunció en su mensaje de asunción a la Legislatura que se proponía hacer un "gobierno definitivamente agrario". Estuvo al frente del ejecutivo hasta junio de 1935, debiendo afrontar el momento más difícil de la crisis de esa década. Fueron años de intensa actividad política, incluyendo la sanción de la Constitución Provincial de 1933, Ilamada a regir hasta 2008. Concluyendo la gestión de Etchevehere, en las elecciones de marzo de 1935, ganó la fórmula radical conformada por Eduardo Tibiletti y Roberto Lanús, quienes habían logrado la unificación del radicalismo, con excepción de un grupo minoritario de yrigoyenistas.

La gestión de Tibiletti finalizó normalmente con el llamado a elecciones y el cambio de gobierno. Los comicios de 1939 consagraron la fórmula radical Enrique Mihura-Cipriano Marcó, quienes asumieron el $1^{\circ}$ de junio de ese año. La gobernación de Mihura concluyó de manera abrupta con la intervención federal dictada a todas las provincias por el golpe del 4 de junio de 1943, que derrocó al presidente Ramón Castillo. El gobernador encabezó una "resistencia simbólica", negándose a entregar el mando, pese a lo cual terminó siendo destituido por la fuerza (Arce, 1979).

La gestión gubernamental de aquellos años planteó desafíos inéditos a la dirigencia política, derivados del contexto de crisis económica global y agravada por una fuerte invasión de langostas en varias campañas y una dura sequía en 1933. Las finanzas públicas del Estado provincial observaron un déficit permanente en esa etapa, afectadas por la acumulación de deudas y las dificultades para la colocación de nuevos títulos. Ello se reflejó en retrasos en los pagos de haberes e incluso en "descuentos forzosos" en los sueldos de funcionarios y empleados públicos (Mathieu et al., 2017, p. 92).

En tal escenario, las oportunidades de respuestas estatales frente a la debacle económica aparecían acotadas. Sin embargo, los gobiernos radicales impulsaron diversas medidas tendientes a paliar la situación: se impulsó la colonización agraria, se brindó apoyo público para el combate de plagas (langosta), se entregaron semillas a los pequeños agricultores que perdían la cosecha (trigo, lino y en menor medida maíz); en 1935 se creó el Banco de Entre Ríos a fin de impulsar el crédito agrario y consolidar la situación de diversos bancos regionales, 
se financiaron algunos frigoríficos con recursos públicos, se sancionaron normas de apoyo al cooperativismo, a la diversificación de la producción y a la introducción de nuevas técnicas, etc. (Biasizo, 2015; Reula, 1971). La propia Constitución de 1933 ofrece un ejemplo de las avanzadas concepciones de la dirigencia conservadora: el artículo $37^{\circ}$ de la Carta Magna vernácula reza:

El Estado fomentará y protegerá la producción y, en especial, las industrias madres y las transformadoras de la producción rural, a cuyo objeto podrá conceder, con carácter temporario, primas, recompensas de estímulo, exoneración de impuestos y contribuciones u otros beneficios compatibles con esta Constitución; o concurrir a la formación de sus capitales, y al de los ya existentes, participando de la dirección y de la distribución de sus beneficios. Igualmente fomentará y orientará la aplicación de todo sistema, instrumento o procedimiento, que tienda a facilitar la comercialización de la producción, aunque para ello deba acudir con sus recursos o crédito. (Constitución Provincial de 1933)

Pese al esfuerzo y las buenas intenciones, la situación no dejó de ser en extremo complicada: "un intenso drama económico sacudió a esta provincia desde 1929" (J. Malenoski (citado en Mathieu et al., 2017, p. 83). El Ministro de Hacienda, Luis Rodríguez, expresó claramente la profundidad de la crisis en la Memoria del Ministerio de 1935:

Nuestros agricultores, en su mayor parte, se encuentran sumidos en la indigencia. Sus herramientas desgastadas por una labor sin compensación, sus animales de trabajo inservibles, sin crédito en el comercio y amenazados constantemente por los acreedores. No están en mejor situación los ganaderos que... debieron liquidar las haciendas a precios mínimos. Por eso se observa, principalmente en el norte, una despoblación de los campos... (citado en Mathieu et al., 2017, p. 83)

En fin, la pérdida de población rural, el desempleo y la pobreza creciente fueron los corolarios necesarios de la dura situación provincial. Un índice claro de la profundidad de la crisis lo constituye el valor de las exportaciones realizadas por puertos entrerrianos: si en 1930 alcanzaron 127 millones de pesos oro, en 1933 apenas sumaron 40 millones de pesos oro. Vale decir, 87 millones de pesos oro menos en sólo un trienio (Biasizo, 2015, p. 18, extraído de Arnau, 1935); según la memoria del Ministerio de Hacienda de 1938, la situación fue aún peor.

Parte de esta problemática se explica por la sequía y la merma en las cosechas, en especial de trigo y lino (Reula, 1971, p. 132). En los años posteriores, las exportaciones se recuperaron, pero siempre en un nivel inferior al de 1930 (Memoria Ministerio de Hacienda, 1938, p. XVII). Los giros bancarios, el precio de la tierra y los préstamos hipotecarios también reflejaron la profundidad de la crisis (Síntesis Estadística, Ministerio de Gobierno). En términos generales, la recesión fue más pronunciada en 1932-35, a partir de lo cual se observa cierta recuperación hasta inicios de la guerra, donde nuevamente la economía se estanca, con un impacto diferencial en las distintas actividades.

En definitiva, si bien es probable que los problemas en las finanzas públicas, el empleo y la situación social tengan raíces más profundas en el impacto de la acumulación capitalista sobre una estructura productiva vernácula escasamente diversificada y dominada por las actividades agrícola-ganaderas (Leyes, 2013), lo cierto es que la Gran Depresión del siglo xx, golpeó la economía provincial. Es imposible que ello no suceda en un contexto donde los precios ex- 
ternos del trigo, el lino y el maíz -principales cultivos locales- cayeron alrededor del $40 \%$ al 45\% entre fines de la década de 1920 e inicios de la de 1930 (promedio 1931-33 respecto del promedio 1927-29), mientras el valor de la carne vacuna se reducía un $26 \%$ y el de los cueros vacunos un $50 \%$ en igual lapso (Barsky y Gelman, 2009, p. 313). De allí que la profundidad de la crisis económica entrerriana se comprenda cabalmente mediante el examen de la estructura productiva. Todavía en 1946, a pesar del importante crecimiento industrial desde mediados de la década de 1930, las producciones rurales (agropecuarias) absorbían casi el 40\% de la ocupación entrerriana, mientras la industria empleaba sólo el 17\% de la población ocupada (Censo de Población 1947, tomo I: 245). La misma fuente indica que en la provincia de Buenos Aires trabajaban en la industria el 33\% de los ocupados y en Santa Fe el 23\% (Censo de Población 1947, tomo I: 145 y 197; tomo II: 396). Durante la década de 1930, el 90\% de los productos que Entre Ríos vendía en los mercados nacional e internacional eran productos primarios o de origen agropecuario (Síntesis Estadística, varios números).

En ese contexto general, conviene examinar brevemente las dos actividades principales: agricultura extensiva y ganadería. En cuanto a la primera, el lapso 1931-36 evidenció un estancamiento en la expansión del área sembrada -incluso una caída en el caso del trigo, lo que llevó a una reducción de alrededor del $50 \%$ en la producción de trigo, lino y maíz respecto del período 1926-1931 (Censo Agropecuario, 1939). Esta situación está claramente asociada a la crisis externa, pero también a problemas climáticos y a la reaparición de plagas (langosta) que afectaron el área cosechada y la producción. La campaña 1936-37 mostró un leve repunte en la actividad triguera y una mejora sustancial en el cultivo de maíz respecto del promedio 1931-36, aunque expresa una caída en el volumen cosechado de lino. En total se cultivaron 1.355.600 hectáreas en esa campaña de los tres principales cultivos. En la campaña 1937-38 la producción agrícola se recuperó significativamente: el área sembrada con trigo, lino y maíz ya suma 1.437.300 has. En la campaña 1938-39 se logró superar el millón de toneladas de producción de trigo, lino y maíz (CFI \& Coprode, 1967, cuadros 84, 91 y 98), acompañando a las tesis de Gravil (1970) acerca del papel de la agricultura en la rápida salida de la Depresión en Argentina.

Sin embargo, el comienzo de la Segunda Guerra Mundial vuelve a complicar la situación de los principales cultivos pampeanos, para los que se observa una reducción de la superficie sembrada en los años del conflicto, lo que dificulta la recuperación de la economía vernácula. Es importante consignar, de todas maneras, que la agricultura pampeana en Entre Ríos ingresó en una etapa de estancamiento que fue mucho más allá de la década de 1930, prolongándose hasta mediados los años sesenta. Por lo demás, la década de 1930 también expresa el avance de otros cultivos, como el arroz y el girasol, cuya superficie sembrada crece de manera considerable.

La actividad ganadera, por su parte, "primera en importancia económica" según Reula, (1971, p. 141), también se vio afectada por la crisis, además por una sequía en 1933. Entre 1930 y 1934 una sequía de 1933 mediante, se observa una reducción del stock de ganado bovino de un $23 \%$, alcanzando 1.952 .468 vacunos (582 mil cabezas menos que en 1930). El lanar se derrumbó aún más, perdiendo un millón y medio de cabezas entre 1930 y 1934 . Otro tanto sucedió con el ganado porcino, caballar, mular y caprino (Memoria Ministerio de Hacienda, 1937, p. 328 y CFI y Coprode, 1967). En el caso del vacuno, es propio del ciclo ganadero la reducción del stock de hacienda cuando bajan los precios, en la medida en que los productores

tiempo\&economía

Vol. 5 N. 2 - Julio - Diciembre del 2018 
deben comercializar hembras (vaquillonas y vacas) para recomponer sus ingresos. Durante los años de la Segunda Guerra Mundial los precios ganaderos crecieron y la actividad mantuvo un buen desempeño, junto con la faena frigorífica, en línea con el contexto nacional.

Finalmente, según algunos análisis, las condiciones infraestructurales no parecen haber ayudado a la resolución de la crisis en la provincia. El aislamiento natural de Entre Ríos se veía agravado por las dificultades de acceso a puertos y estaciones ferroviarias. Según datos del Censo de Economía Rural, el 18\% de las explotaciones agropecuarias clasificadas tenía una distancia a un puerto o estación de ferrocarril superior a los 25 kilómetros, mientras que en Buenos Aires tal porcentaje era del 6\% y en Santa Fe del 4,2\% (Ministerio de Agricultura, 1940a, p. 591). La densidad de vías férreas seguía siendo inferior en Entre Ríos respecto de las provincias citadas. Las dificultades de transporte se expresan cabalmente en la intención de crear una flota estatal de barcos en Entre Ríos para el comercio en los ríos Uruguay y Paraná (EI Orden, viernes 28 de abril de 1944). De todas maneras, es relevante destacar que hacia 1945 existían 2.074,9 km de vías férreas en Entre Ríos, con 129 estaciones (Síntesis Estadística 194445, p. 63). Luego de la década de 1930 la inversión ferroviaria se paralizó, lo que también se explica por la difusión de otros medios de transporte de cargas.

\section{La estructura productiva de Entre Ríos a partir del censo rural de 1937}

En primer lugar, vamos a presentar la superficie puesta en valor para actividades agrarias, que para el total de la provincia ascendía a 6.466 .956 hectáreas, de las cuales el 93,6\%, es decir 5.986.765 hectáreas han sido puestas en producción y solo 480.191 hectáreas fueron consideradas inapropiadas para la producción agraria. De la tierra productiva, la mayor proporción estaba dedicada al pastoreo de animales (40,6\%), mientras que la producción agrícola, incluyendo agricultura, silvicultura y fruticultura ocupaban en conjunto casi el 52\%, repartidos en un $28,7 \%$ en la agricultura propiamente dicha y el $23,2 \%$ en la producción silvícola y frutícola.

Diamante era el departamento con menos territorio productivo (227.042 ha), mientras que Gualeguaychú era el de mayor extensión aprovechable (1.083.785 ha). También este último el de mayor superficie inopia (17\%) teniendo en su opuesto a Nogoyá como el departamento de menor superficie improductiva (0,4\%). Paraná es el departamento que más hectáreas dedica a los cultivos (274.894 ha) y Feliciano el que menos (11.810 ha). Gualeguaychú por su parte dedicaba la mayor superficie al pastoreo (572.661 ha), mientras que Feliciano también el que menos, aunque seis veces más que a los cultivos (75.368 ha). La Paz se destaca por tener la mayor superficie dedicada al monte natural o cultivado (406.457 ha) mientras que Diamante el que menos (10.140 ha).

En cuanto a la proporción de cada departamento dedicada a las producciones agrarias, tenemos tres distritos equilibrados entre cultivos y pastoreo (Diamante, Colón y Uruguay), tres con supremacía neta de la agricultura (Tala, Nogoyá y Paraná), cinco eminentemente ganaderos (Federación, Concordia, Victoria, Gualeguay y Gualeguaychú) y en tres con predominio de monte (Feliciano, Villaguay y La Paz). 
Tabla 4. Distribución del uso del suelo en Entre Ríos en 1937

\begin{tabular}{|c|c|c|c|c|c|c|c|c|c|}
\hline \multirow[b]{2}{*}{ Departamento } & \multicolumn{5}{|c|}{ Hectáreas } & \multicolumn{4}{|c|}{$\%$} \\
\hline & Cultivada & Pastoreo & $\begin{array}{c}\text { Monte } \\
\text { natural y } \\
\text { cultivado }\end{array}$ & Inopia & Total & Cultivada & Pastoreo & $\begin{array}{c}\text { Monte } \\
\text { natural y } \\
\text { cultivado }\end{array}$ & Inopia \\
\hline Colón & 105478 & 136763 & 19191 & 11709 & 273141 & 38,6 & 50,1 & 7,0 & 4,3 \\
\hline Concordia & 81109 & 228360 & 194875 & 28016 & 532360 & 15,2 & 42,9 & 36,6 & 5,3 \\
\hline Diamante & 95864 & 109484 & 10140 & 11554 & 227042 & 42,2 & 48,2 & 4,5 & 5,1 \\
\hline Federación & 54266 & 178396 & 71551 & 20743 & 324956 & 16,7 & 54,9 & 22,0 & 6,4 \\
\hline Gualeguay & 111221 & 297909 & 21433 & 46439 & 477002 & 23,3 & 62,5 & 4,5 & 9,7 \\
\hline Gualeguaychú & 217158 & 572661 & 109830 & 184136 & 1083785 & 20,0 & 52,8 & 10,1 & 17,0 \\
\hline La Paz & 130728 & 137588 & 406457 & 28994 & 703767 & 18,6 & 19,6 & 57,8 & 4,1 \\
\hline Nogoyá & 198457 & 136614 & 44067 & 1592 & 380730 & 52,1 & 35,9 & 11,6 & 0,4 \\
\hline Paraná & 274894 & 96184 & 75171 & 16439 & 462688 & 59,4 & 20,8 & 16,2 & 3,6 \\
\hline Tala & 117921 & 85099 & 49232 & 8460 & 260712 & 45,2 & 32,6 & 18,9 & 3,2 \\
\hline Feliciano & 11810 & 75368 & 200147 & 13352 & 300677 & 3,9 & 25,1 & 66,6 & 4,4 \\
\hline Uruguay & 201861 & 190595 & 51582 & 38754 & 482792 & 41,8 & 39,5 & 10,7 & 8,0 \\
\hline Victoria & 104698 & 194270 & 13691 & 47570 & 360229 & 29,1 & 53,9 & 3,8 & 13,2 \\
\hline Villaguay & 153653 & 188449 & 232540 & 22433 & 597075 & 25,7 & 31,6 & 38,9 & 3,8 \\
\hline Total & 1859118 & 2627740 & 1499907 & 480191 & 6466956 & 28,7 & 40,6 & 23,2 & 7,4 \\
\hline
\end{tabular}

Fuente: elaboración propia

Mapa 2. Distribución del uso del suelo en Entre Ríos en 1937

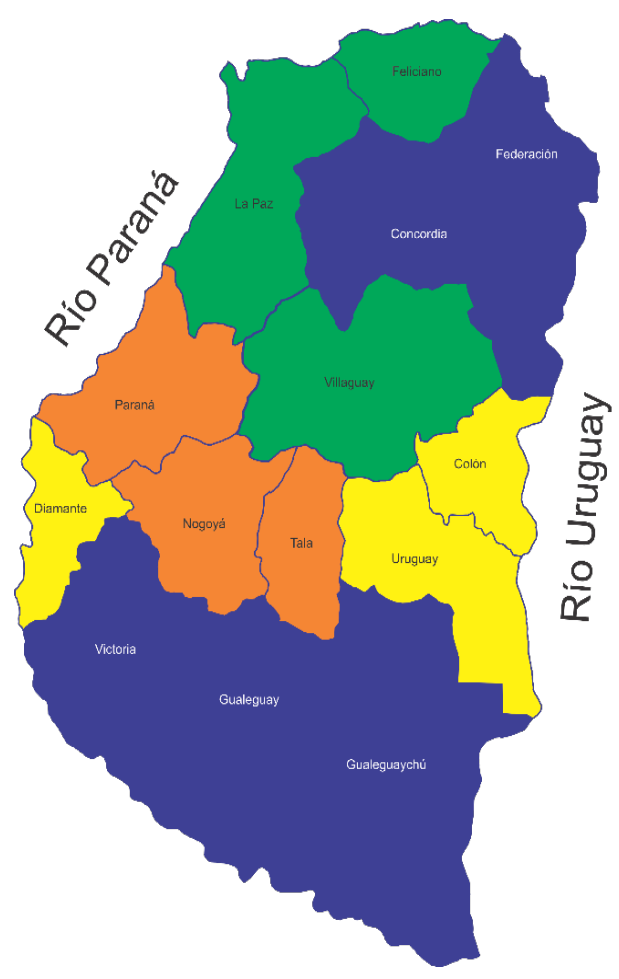

Equilibrio entre pastoreo y cultivo

Predominio de los cultivos

Predominio de la ganadería

Predominio del monte natural o cultivado

tiempo\&economía

Vol. 5 N. ${ }^{\circ} 2$ - Julio - Diciembre del 2018

p. 191

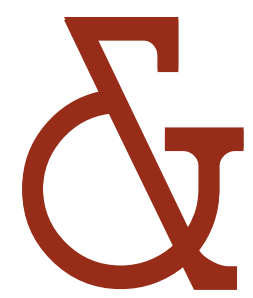


Como podemos ver en el Mapa 2, esta distribución configura dos sectores ganaderos netos al sur y al noroeste, tres agrícolas y otros tres equilibrados entre los destinos agrícolas y ganaderos que cruzan el centro de la provincia, y en el noroeste predominan las explotaciones forestales y frutícolas.

En tanto a la cantidad de establecimientos agropecuarios, el censo registró 31.931. De ellos, las chacras eran muy mayoritarias con el $62,3 \%$ del total, seguidas de las estancias mixtas con el $8,6 \%$, las estancias de cría con el 5,1\%, los cuales eran definidos como "con ganadería" con $1,7 \%$, quintas y montes forestales con el $1 \%$, tambos con el $0,6 \%$, montes forestales con el $0,4 \%$, huertas con el $0,2 \%$ e invernada con el $0,1 \%$. Entre todos estos establecimientos concentran el $81,2 \%$ de todos los productivos. Multiplicados estos por su superficie media tenemos que las chacras cubrían el $29,5 \%$ de la superficie de la provincia (1.717.093,5 ha), las estancias mixtas el 30,9\% (1.800.019,2 ha), las estancias de cría el 20\% (1.162.703,1 ha) y los establecimientos "con ganadería" 2 el 16,6\% (964360,2 ha). Todos estos establecimientos en conjunto representan, aproximadamente el $87,3 \%$ de las 6.466 .956 ha productivas de la provincia.

Tabla 5. Principales unidades productivas agrarias y sus características

\begin{tabular}{|c|c|c|c|c|c|}
\hline Tipo de unidad productiva & Cantidad & \% del total & Superficie & $\begin{array}{c}\text { Superficie } \\
\text { aproximada }\end{array}$ & $\%$ del total \\
\hline Chacras & 19805 & 62,3 & 86,7 & 1717093,5 & 29,5 \\
\hline Estancias mixtas & 5448 & 8,6 & 330,4 & 1800019,2 & 30,9 \\
\hline Estancias de cría & 3211 & 5,1 & 362,1 & 1162703,1 & 20,0 \\
\hline Con ganadería & 1102 & 1,7 & 875,1 & 964360,2 & 16,6 \\
\hline Quintas & 655 & 1,0 & 9,5 & 6222,5 & 0,1 \\
\hline Montes frutales & 651 & 1,0 & 32,3 & 21027,3 & 0,4 \\
\hline Tambos & 400 & 0,6 & 70,8 & 28320 & 0,5 \\
\hline Montes forestales & 273 & 0,4 & 159,9 & 43652,7 & 0,7 \\
\hline Huertas & 137 & 0,2 & 14,4 & 1972,8 & 0,0 \\
\hline Invernada & 85 & 0,1 & 889,8 & 75633 & 1,3 \\
\hline Subtotal & 31767 & 81,2 & & 5821004,3 & 100,0 \\
\hline
\end{tabular}

Fuente: elaboración propia

La distribución espacial de estas unidades agropecuarias según la superficie sobre la que se desplegaban, muestra la mayor concentración de chacras en Paraná $(44,8 \%)$, las estancias mixtas agro-ganaderas en Colón (49,4\%), las estancias de cría en Rosario del Tala $(42,4 \%)$, los establecimientos con ganadería en La Paz (29,5\%), y el resto se repartía en valores mínimos.

Como puede verse en la Tabla 6, estas cuatro unidades agropecuarias ocupaban en los 14 departamentos por encima del $90 \%$ de la superficie de cada uno, salvo en Gualeguaychú que apenas Ilega a ese valor.

2 "Agrúpanse bajo este título aquellas explotaciones que poseen cierto número de ganado y que no han podido clasificarse en ninguno de los otros rubros" (Ministerio de Agricultura, 1940b, p. 20). 
Tabla 6. Tipo de unidad productiva por departamento en porcentajes en 1937

\begin{tabular}{|c|c|c|c|c|c|c|c|c|c|c|c|c|c|c|}
\hline $\begin{array}{c}\text { Unidades } \\
\text { agropecuarias }\end{array}$ & $\frac{\circ}{9}$ & $\begin{array}{l}\frac{\hat{0}}{2} \\
\frac{\hat{0}}{2} \\
\frac{2}{2}\end{array}$ & 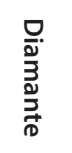 & $\begin{array}{l}\frac{1}{10} \\
\frac{0}{0} \\
\frac{1}{2} \\
\frac{2}{0} \\
\frac{0}{3}\end{array}$ & 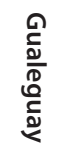 & 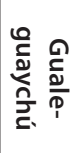 & $\begin{array}{l}\text { ๊ } \\
\text { กี่ }\end{array}$ & $\begin{array}{l}z \\
\text { o } \\
\vdots \\
\vdots \\
\vdots\end{array}$ & 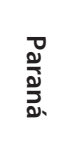 & $\frac{\vec{Q}}{\mathrm{Q}}$ & 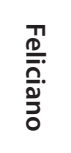 & 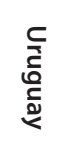 & $\begin{array}{l}\text { â. } \\
\frac{\hat{0}}{3} \\
\frac{0}{2}\end{array}$ & 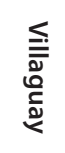 \\
\hline Chacras & 35,2 & 19,6 & 33,6 & 36,5 & 24,5 & 18,7 & 22,6 & 37,4 & 44,8 & 35,7 & 10,2 & 47,0 & 17,2 & 24,3 \\
\hline Estancias mixtas & 49,4 & 34,8 & 36,2 & 23,0 & 20,8 & 23,5 & 31,1 & 33,1 & 34,7 & 38,7 & 17,5 & 32,6 & 28,9 & 30,3 \\
\hline Estancias de cría & 9,0 & 22,7 & 15,3 & 11,5 & 24,1 & 27,5 & 29,5 & 17,5 & 9,4 & 16,7 & 42,4 & 8,9 & 27,0 & 25,2 \\
\hline $\begin{array}{l}\text { Est. con } \\
\text { ganadería }\end{array}$ & 4,8 & 16,8 & 12,8 & 28,0 & 26,2 & 20,2 & 15,1 & 16,8 & 8,6 & 8,4 & 29,4 & 10,4 & 24,9 & 18,7 \\
\hline Quintas & 0,2 & 0,2 & 0,1 & 0,1 & 0,1 & 0,1 & 0,1 & 0,1 & 0,2 & 0,0 & 0,0 & 0,1 & 0,0 & 0,1 \\
\hline Montes frutales & 0,2 & 2,7 & 0,0 & 0,3 & 0,1 & 1,2 & 0,0 & 0,0 & 0,0 & 0,0 & 0,0 & 0,0 & 0,0 & 0,0 \\
\hline Tambos & 0,4 & 1,6 & 0,6 & 0,3 & 0,4 & 0,3 & 0,5 & 0,2 & 1,2 & 0,2 & 0,0 & 0,5 & 0,1 & 0,2 \\
\hline $\begin{array}{c}\text { Montes } \\
\text { forestales }\end{array}$ & 0,0 & 0,2 & 0,1 & 0,1 & 0,0 & 5,2 & 0,4 & 0,4 & 0,1 & 0,1 & 0,4 & 0,0 & 0,1 & 0,2 \\
\hline Huertas & 0,0 & 0,0 & 0,0 & 0,0 & 0,1 & 0,0 & 0,0 & 0,0 & 0,1 & 0,0 & 0,0 & 0,1 & 0,0 & 0,0 \\
\hline $\begin{array}{l}\text { Estancias de } \\
\text { invernada }\end{array}$ & 0,8 & 1,4 & 1,3 & 0,3 & 3,8 & 3,3 & 0,7 & 1,3 & 0,8 & 0,3 & 0,0 & 0,4 & 1,8 & 1,0 \\
\hline
\end{tabular}

Fuente: elaboración propia

Las chacras registradas en el censo fueron discriminadas en doce categorías distintas, desde las que tienen una extensión no mayor de 5 hectáreas hasta las que exceden de las 625 . En la provincia de Entre Ríos constituyen el tipo de unidad productiva por lejos dominante, con 19805 establecimientos, constituyendo el 62\% del total. Las categorías que abarcan mayor número de explotaciones de este tipo en Entre Ríos, son las de más de 25 y hasta 50, que suman 4370 chacras, o sea el 22,1\% del total ya citado. Se ha establecido una superficie media de 86,7 , la cual importa una superficie aproximada de 1717093,5 hectáreas cubiertas por este tipo de actividad. Este tipo de establecimiento productivo se encuentra presente en los 14 departamentos que existían en ese entonces. El departamento de Paraná concentraba la mayor cantidad, 2994 casos (15,1\%) seguido por el de Uruguay con 2505 (12,6\%). En el otro extremo, San José Feliciano tiene el menor porcentaje de estas unidades productivas, 319 (1,6\%).

\section{La producción}

El primer dato destacable es que considerando los cuatro censos agropecuarios anteriores al de 1937 y ese mismo registro, se verifica por un lado un incremento progresivo del área sembrada, donde destacan el lino y el maíz y como contracara la disminución del stock ganadero de vacunos y ovinos y un leve repunte de los porcinos.

La composición de los valores de las exportaciones portuarias de ese año refleja esta realidad. En 1937 se exportaron 54.238.368,9 \$ oro $^{\circ}$ Los productos derivados de la ganadería (animales vivos, despojos de animales, materias animales elaboradas y residuos de animales) representaron el 33,2\%, contra 50,3\% de los productos agrícolas (materias primas, vegetales elaboradas y residuos vegetales). De estas exportaciones, el $37 \%$ de las ganaderas fue directamente al extranjero y el $62,6 \%$ a otros puertos argentinos. Por su parte el $48,7 \%$ de las 
exportaciones agropecuarias fue al extranjero directamente y el 51,3\% a otros puertos como proveedor o feeder (Provincia de Entre Ríos, 1937, p. 39). ${ }^{3}$

Tabla 7. Área sembrada de los tres productos principales y del stock de los productos principales de la ganadería, Entre Ríos, 1888 y 1947, censos agropecuarios

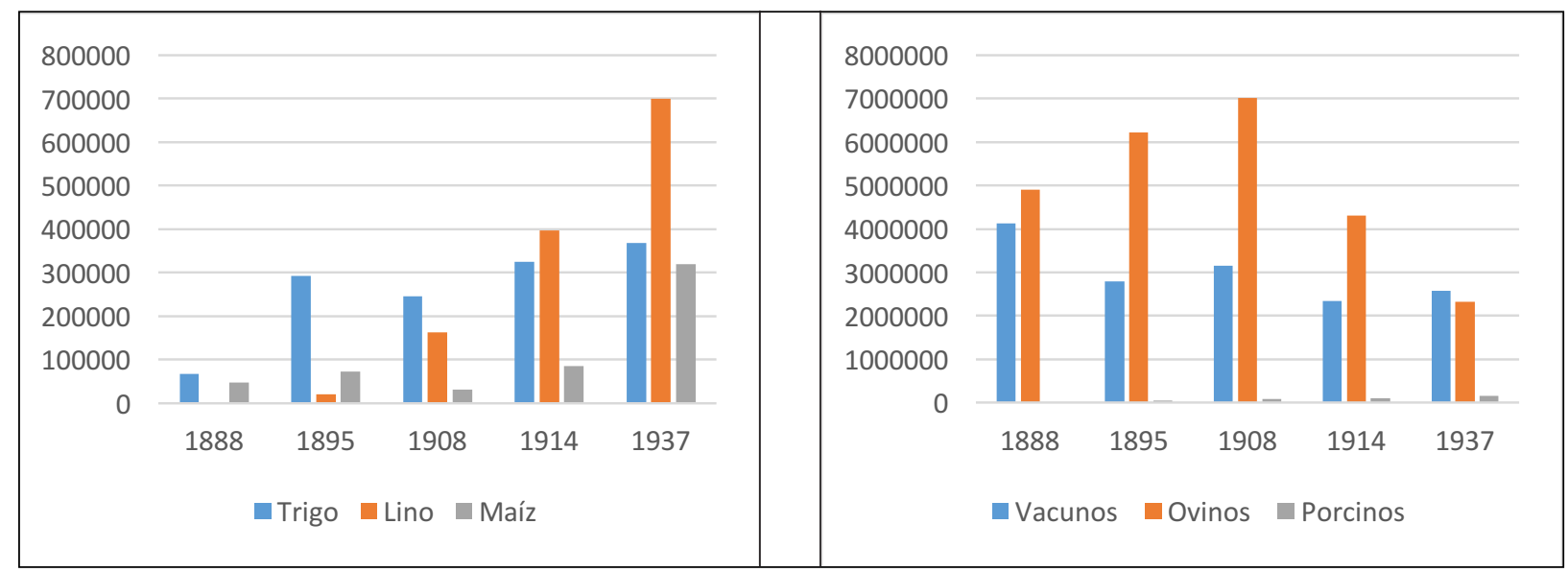

Fuente: Censo Nacional Agropecuario

En cuanto a la agricultura, considerando el trigo, Paraná concentraba la mayor parte de las unidades productivas $(18,3 \%)$, de la superficie sembrada $(21,4 \%)$ y de la producción $(18,5 \%)$. En el otro extremo, en Feliciano, prácticamente no se registra producción triguera. El lino presenta un panorama similar con Paraná dominando todos los indicadores y Feliciano en el extremo opuesto. Con valores similares se presenta el maíz, aunque Feliciano en este caso presenta una participación algo mayor.

El Mapa 3 muestra los departamentos que superan el 10\% de la producción de los tres cereales y oleaginosas principales. Podemos ver que son los departamentos del centro y del sur aquellos que concentran la mayor parte de estos cereales.

Los departamentos de Tala y Victoria concentran respectivamente el 5\% del maíz, el 6,5\% del lino y $6,7 \%$ del trigo y $1,6 \%$ del trigo, $7,8 \%$ del lino e igual porcentaje del maíz, por lo que participan de esta orientación productiva.

El Mapa 5 muestra que la ganadería bovina se concentra en departamentos del sur (Diamante, Tala y Gualeguaychú), La Paz muestra un equilibrio entre ganadería bovina y ovina, en cambio en Feliciano, Concordia (que incluye el territorio que pocos años después será Federal) y Colón predomina la ganadería ovina. Según los Anuarios de Comercio Exterior por los puertos del Uruguay (Colón, Concordia y Gualeguaychú) se extraía lana sucia.

3 La fuente no consigna lo extraído por ferrocarril mediante ferry-boats. 
Mapa 3. Zonas cerealeras y forestales de Entre Ríos en 1937

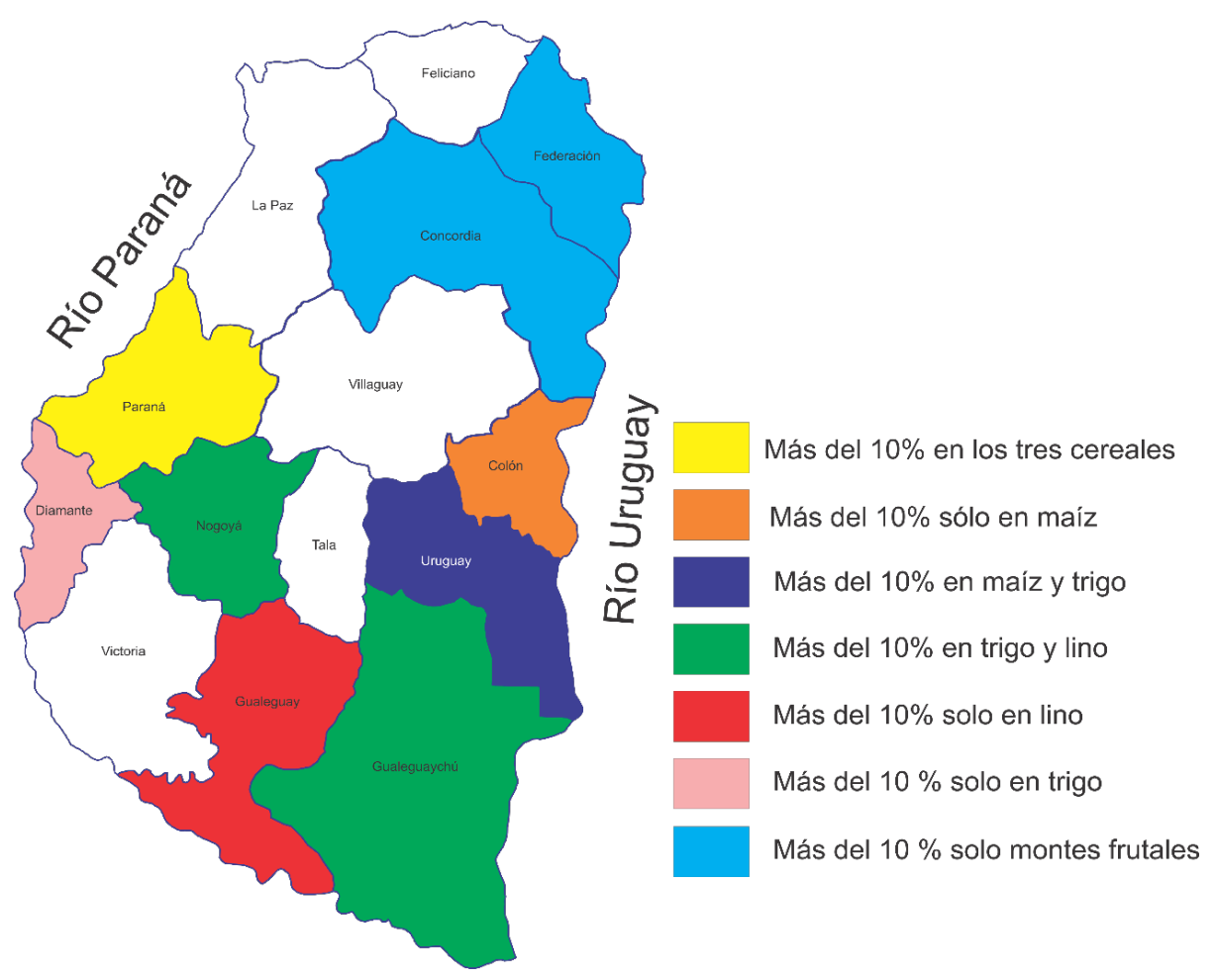

Mapa 4. Zonas de concentración ganadera de Entre Ríos en 1937

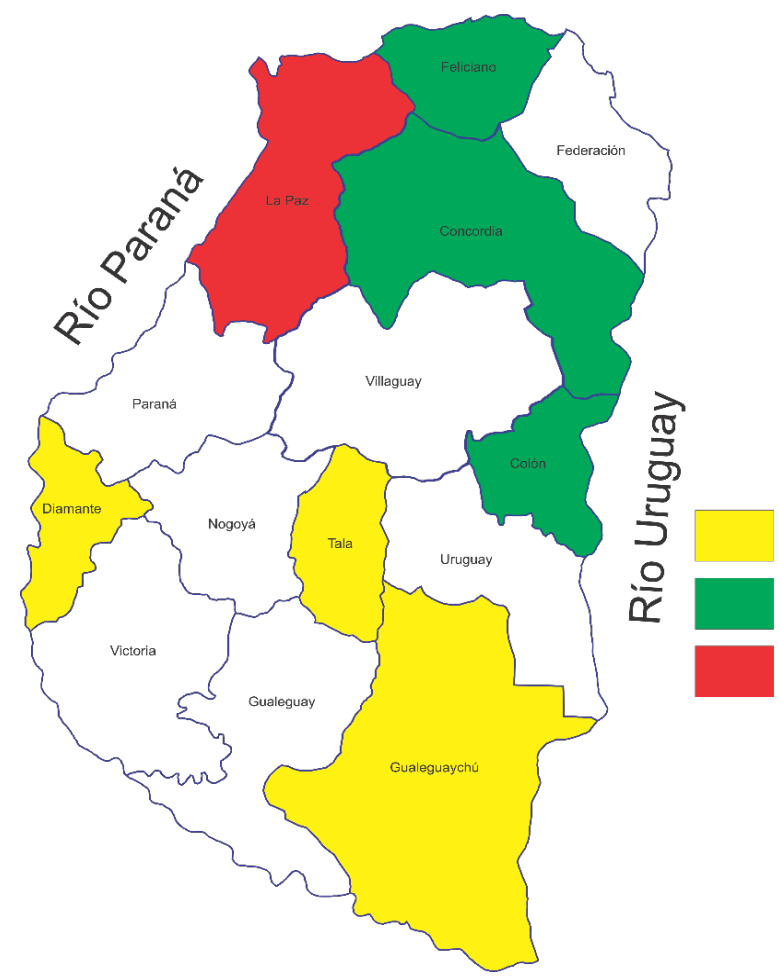

Más del $10 \%$ de los vacunos

Más del $10 \%$ de los lanares

Más del $10 \%$ en ambos ganados 
Tenemos entonces una provincia que se caracterizaba hacia 1937 por su heterogeneidad productiva, pero con algunos rasgos sobresalientes. Hacia el sur la zona ganadera vacuna (lo cual es coherente con la distribución del uso del suelo) y hacia el norte la zona ganadera ovina. Pero al mismo tiempo Gualeguaychú se destacaba en la producción de trigo y lino, Diamante era eminentemente triguero, en Concordia era dominante el monte frutal y Colón era eminentemente maicero en 1937. El maíz era compatible en su estacionalidad con el trigo y el lino ${ }^{4}$ lo que parece haber sido aprovechado en Paraná y Uruguay.

Esta heterogeneidad nos lleva a analizar un fenómeno que si bien ha sido característico en los estudios rurales bonaerenses parece darse también en Entre Ríos que es el avance de la estancia mixta agrícola-ganadera (Palacio, 2002).

Mapa 5. Distribución de las estancias mixtas en Entre Ríos en 1937

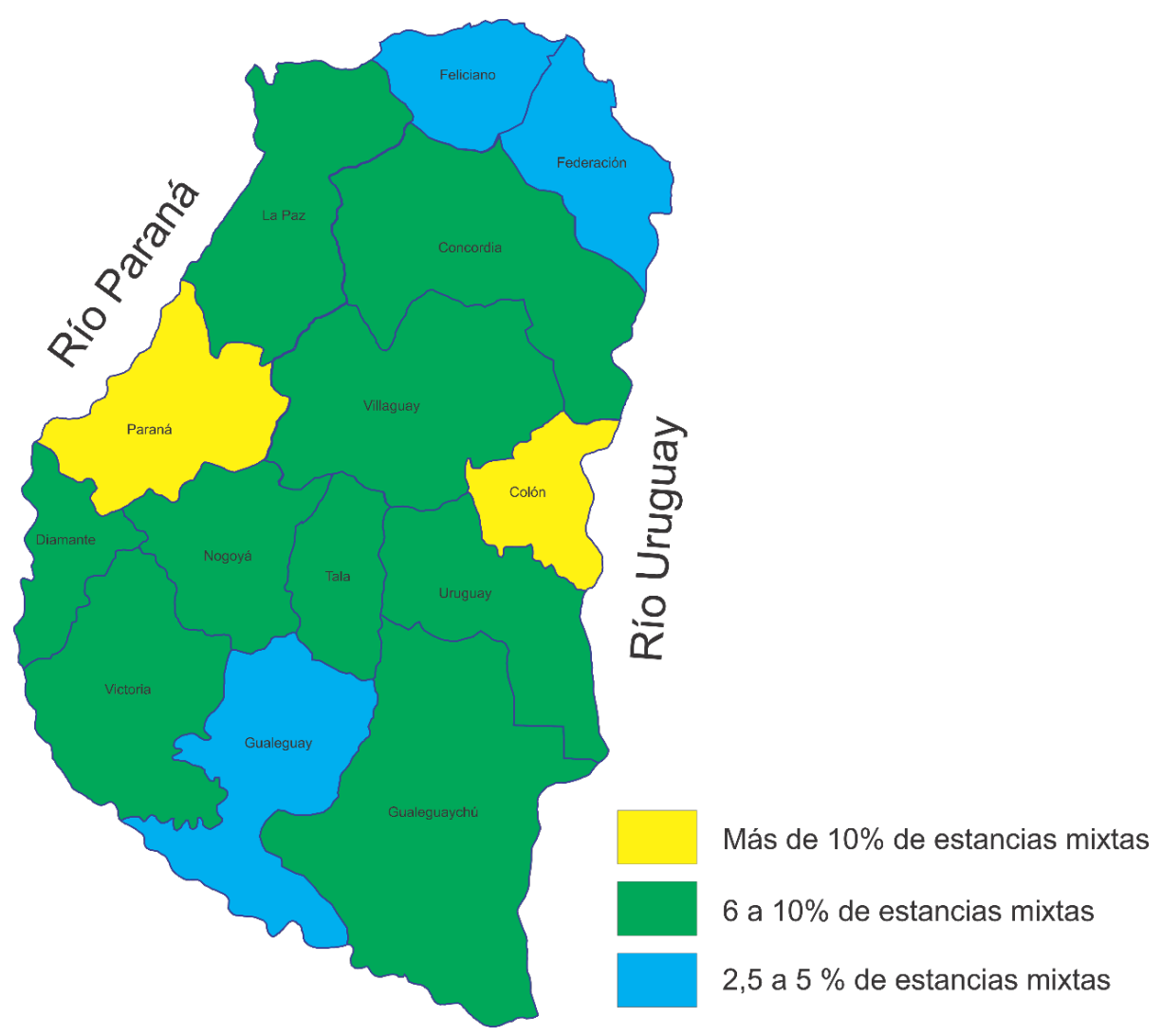

De los 16.331 establecimientos en los cuales fue registrado algún tipo de contrato entre propietario y usufructuante de una explotación agraria, apenas 6.171 (38\%) tenían un registro escrito de la relación contractual. De esos contratos la inmensa mayoría (92\%) se encuentra dentro de los parámetros establecidos por esos años para la estancia mixta, "sistema aquel que

4 El maíz se cosechaba de marzo a mayo y se sembraba de septiembre a octubre; el trigo se sembraba de marzo a mediados de agosto y se cosechaba de septiembre a enero y el lino se sembraba en noviembre y diciembre y se cosechaba entre junio y agosto. 
combinaba la ganadería como actividad dominante en manos de la administración de la estancia con la agricultura que se confiaba a medianos y pequeños arrendatarios" (Palacio, 2002, p. 44), vigentes en ese año con una extensión del contrato en más de un año y menos de 5.

En su versión clásica, este sistema consistía en dividir sus tierras en parcelas de entre 100 y 200 hectáreas y entregarlas en arrendamiento a los agricultores, por el término de tres años. Estos, luego de cultivarlas a un porcentaje de la cosecha durante los primeros años, se comprometían a devolverlas sembradas con forrajeras al final del contrato para, eventualmente, recomenzar el ciclo al año siguiente en otra parcela o estancia. (Palacio, 2002, p. 52)

En tal sentido, y con coherencia con la presencia de estancias mixtas en la provincia, los contratos de arrendamiento existentes como puede observarse en la gráfica 3.

Gráfica 3. Estancias mixtas y contratos entre 1 y 5 años en los departamentos de la provincia de Entre Ríos en 1937

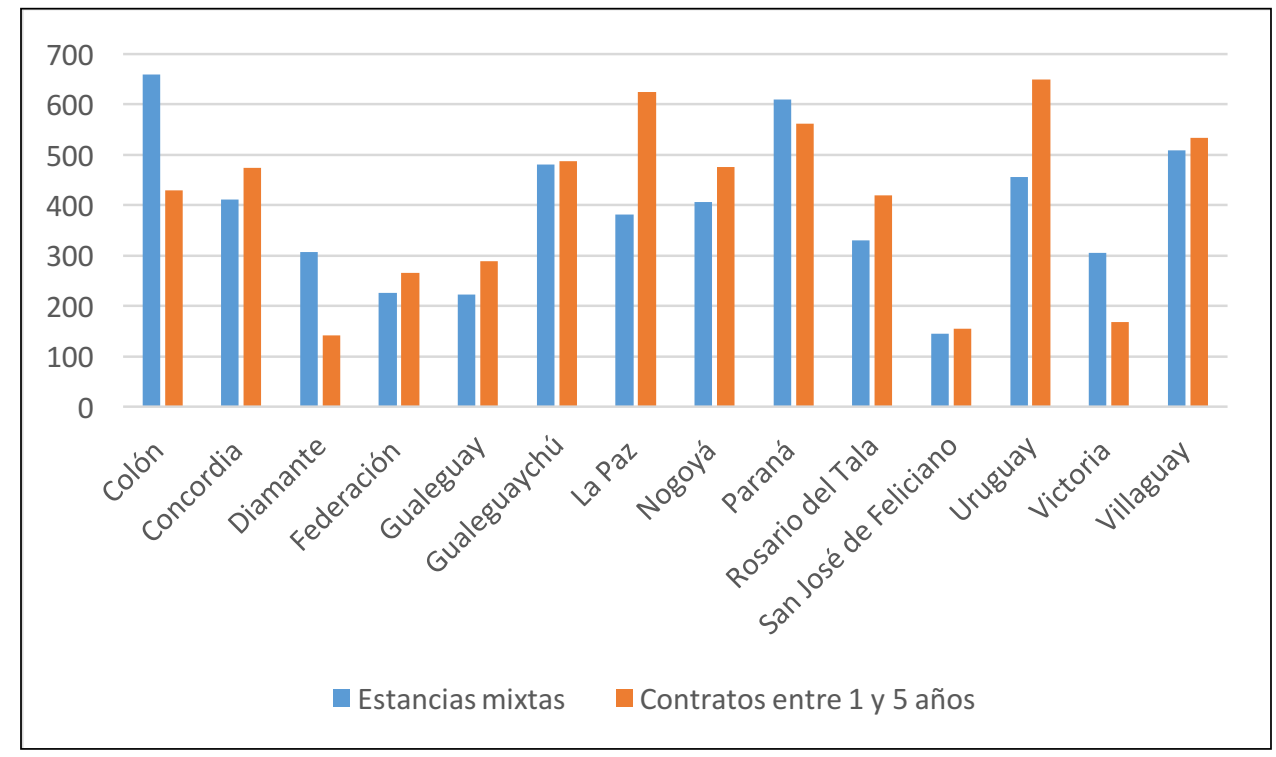

Fuente: Censo Nacional Agropecuario

Sin embargo, se observan diferencias sustantivas en algunos departamentos. Es medianamente equilibrado en Concordia, Federación, Gualeguay, Gualeguaychú, Nogoyá, Paraná, Feliciano y Villaguay; superan ampliamente las estancias mixtas a los contratos en Colón, Diamante y Victoria y lo inverso ocurre en La Paz, Uruguay y en alguna medida en Rosario del Tala.

En el registro también se consultó acerca del tiempo efectivo de residencia de los arrendatarios en la parcela en la que los encontró el censo (gráfica 4). Comparando las estancias mixtas con los tiempos de residencia efectivos al momento del censo podemos apreciar como en la práctica se morigeran bastante los casos excepcionales y salvo en el caso de Colón y Diamante hay más de estos establecimientos que contratos dentro de esos parámetros. De hecho, la media de duración de la estadía pudo ser calculada en 7,4 años, la mediana en 8,4 y la moda en 5 años. 
Gráfica 4. Estancias mixtas y antigüedad de los contratos entre 1 y 5 años en los departamentos de Entre Ríos en 1937

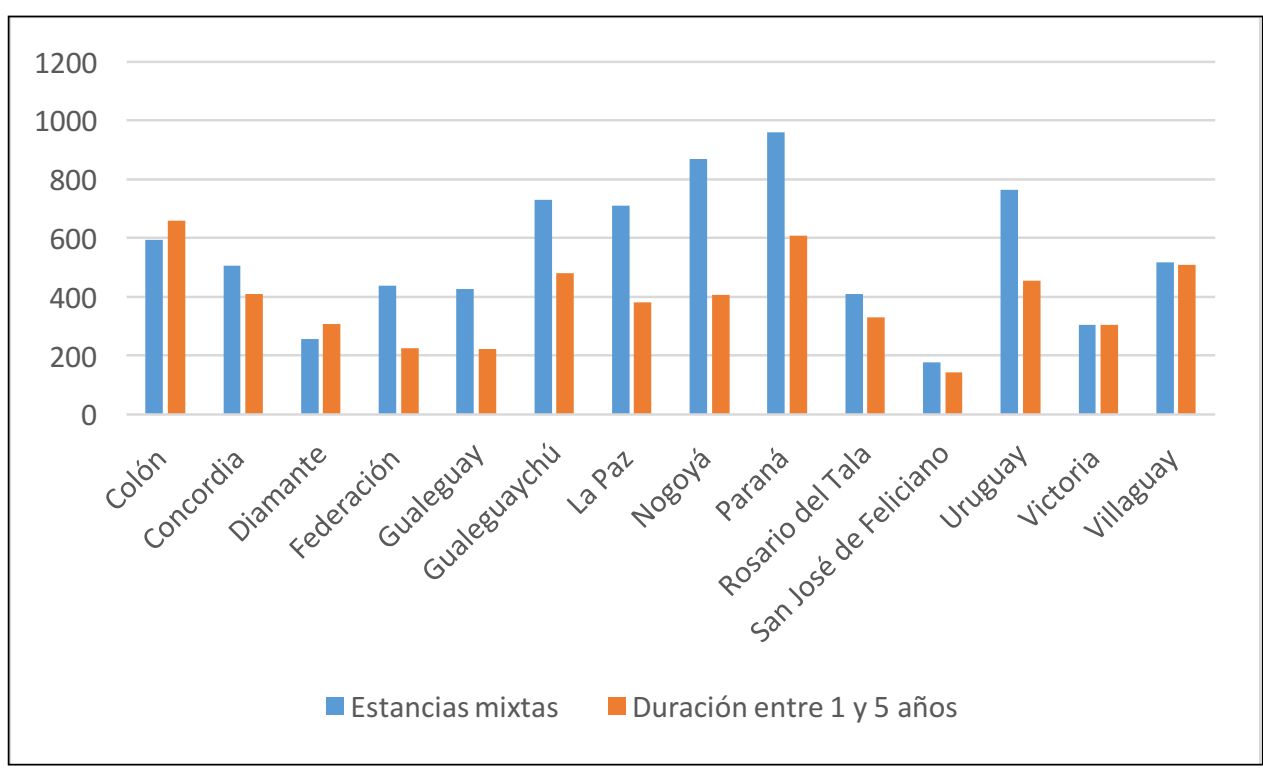

Fuente: Censo Nacional Agropecuario

De todo esto podemos inferir en principio una dominancia menor que a nivel nacional del arrendamiento en la provincia y el consecuente incremento porcentual de la explotación directa de los propietarios.

En segundo lugar, el pago con porcentaje de la cosecha y del procreo de animales de esos arrendamientos por encima de la mitad de los casos, duplicando casi la media nacional al respecto que lo hacía mayormente en dinero. Por último, en este aspecto la existencia de "otras formas" (ocupantes, contratistas, puesteros, etc.) el porcentaje es casi exactamente la mitad que la media nacional, incrementada esta última por los territorios nacionales (Los Andes, ${ }^{5}$ Neuquén, Formosa, Chaco, Misiones, Río Negro y Chubut). Por el contrario, la provincia de Buenos Aires presenta el guarismo menor con apenas 3,9\% de este tipo de relación de producción (Ministerio de Agricultura, 1940a, p. 7).

En cuanto a los contratos, la provincia de Entre Ríos alcanza el mayor porcentual nacional de productores arrendatarios que declararon ocupar los campos que trabajan sin haber firmado contrato con un $62,2 \%$. Es decir, es la provincia con mayor incumplimiento de la Ley $11627 / 32$, cuyo artículo 4 trata de la obligatoriedad de los contratos escritos y protocolizados y las multas que su incumplimiento devengarían.

En este sentido, se destaca la correlación de existencia de contratos escritos con la presencia de estancias mixtas, un fenómeno que al igual que en la provincia de Buenos Aires parece haberse arraigado en Entre Ríos una vez finalizada la Gran Guerra. Probablemente la provincia esté cursando una transición jurídica de la forma de generar relaciones sociales de producción contractuales. Analicemos la gráfica 5 y la tabla 8.

5 La Gobernación de Los Andes o Territorio Nacional de Los Andes fue una división territorial de la República Argentina, que existió entre 1900 y 1943, ubicada casi totalmente en la Puna de Atacama. 
Gráfica 5. Población de Entre Rios dividiendo los territorios en Norte, Sur y Centro

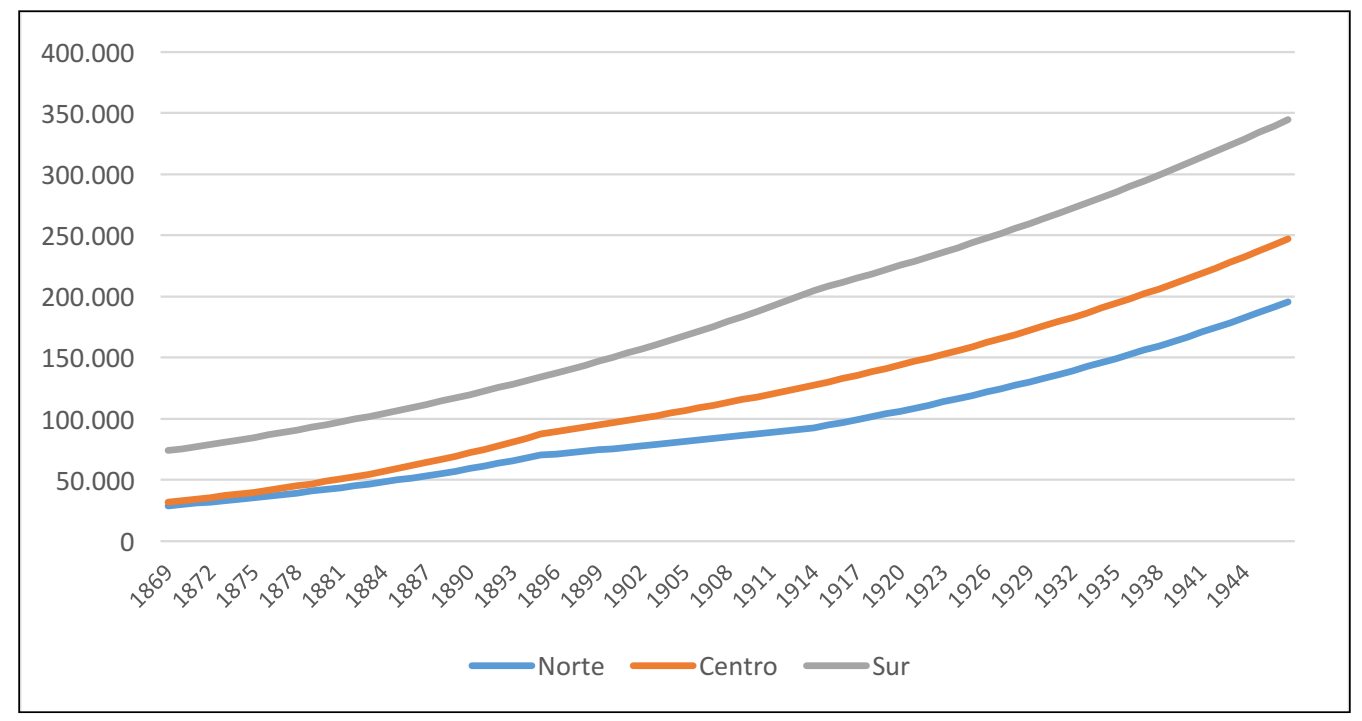

Fuente: Censo Nacional Agropecuario

En principio, la población del sur crece de forma armónica y los censos intermedios entre 1869 y 1947 no llegan a marcarse como hitos. En cambio, vemos una desaceleración del crecimiento a partir de 1895 en el centro y mucho más en el norte. Evidentemente la percepción de despoblamiento rural en el norte puede verificarse como cierta.

Tabla 8. Relación de población urbana y rural entre 1914 y 1947

\begin{tabular}{|c|c|c|c|c|c|c|c|c|}
\hline \multirow{2}{*}{ Sector } & \multicolumn{2}{|c|}{1914} & \multicolumn{2}{|c|}{1947} & \multirow{2}{*}{$\begin{array}{l}\text { Crecimiento } \\
\text { absoluto rural }\end{array}$} & \multirow{2}{*}{$\begin{array}{c}\text { Crecimiento } \\
\text { absoluto } \\
\text { urbana }\end{array}$} & \multirow{2}{*}{$\begin{array}{l}\text { Crecimiento } \% \\
\text { rural }\end{array}$} & \multirow{2}{*}{$\begin{array}{c}\text { Crecimiento \% } \\
\text { urbana }\end{array}$} \\
\hline & Urbana & Rural & Urbana & Rural & & & & \\
\hline Norte & 37,1 & 62,9 & 54,8 & 45,2 & 67286 & 25510 & 195,6 & 115,3 \\
\hline Centro & 40,4 & 59,6 & 56,1 & 43,9 & 89331 & 28165 & 148,9 & 100,8 \\
\hline Sur & 43,7 & 56,3 & 53,1 & 46,9 & 71951 & 35283 & 102,8 & 79,9 \\
\hline Total & 40,9 & 59,1 & 54,7 & 45,3 & 228568 & 88958 & 139,1 & 96,4 \\
\hline
\end{tabular}

Fuente: Censo Nacional Agropecuario

Pero a este fenómeno se le suma otro no menos importante. Si bien todos los sectores incrementan su población entre 1914 y 1947, en todos ellos durante este período se dan procesos de des-ruralización, sobre todo en el norte que perdió casi la mitad de su población rural.

\section{Extracción de la producción}

Esta sección haremos una introducción a la forma de extracción de la producción entrerriana. En principio repetimos, la provincia y la mesopotamia toda aún no se encontraba conectada al continente físicamente. Las formas de extracción eran por vía fluvial a partir de sus puertos sobre el Uruguay y sobre el Paraná, en camión por balsa en Paraná-Santa Fe y 
Victoria-Rosario y en ferry-boat (probablemente también camión) entre Puerto Constanza-Zárate (que entre 1932 y 1945 se llamó José Félix Uriburu en honor al golpista de 1930).

Mapa 6. Rutas, ferrocarriles y puertos en Entre Ríos en 1937

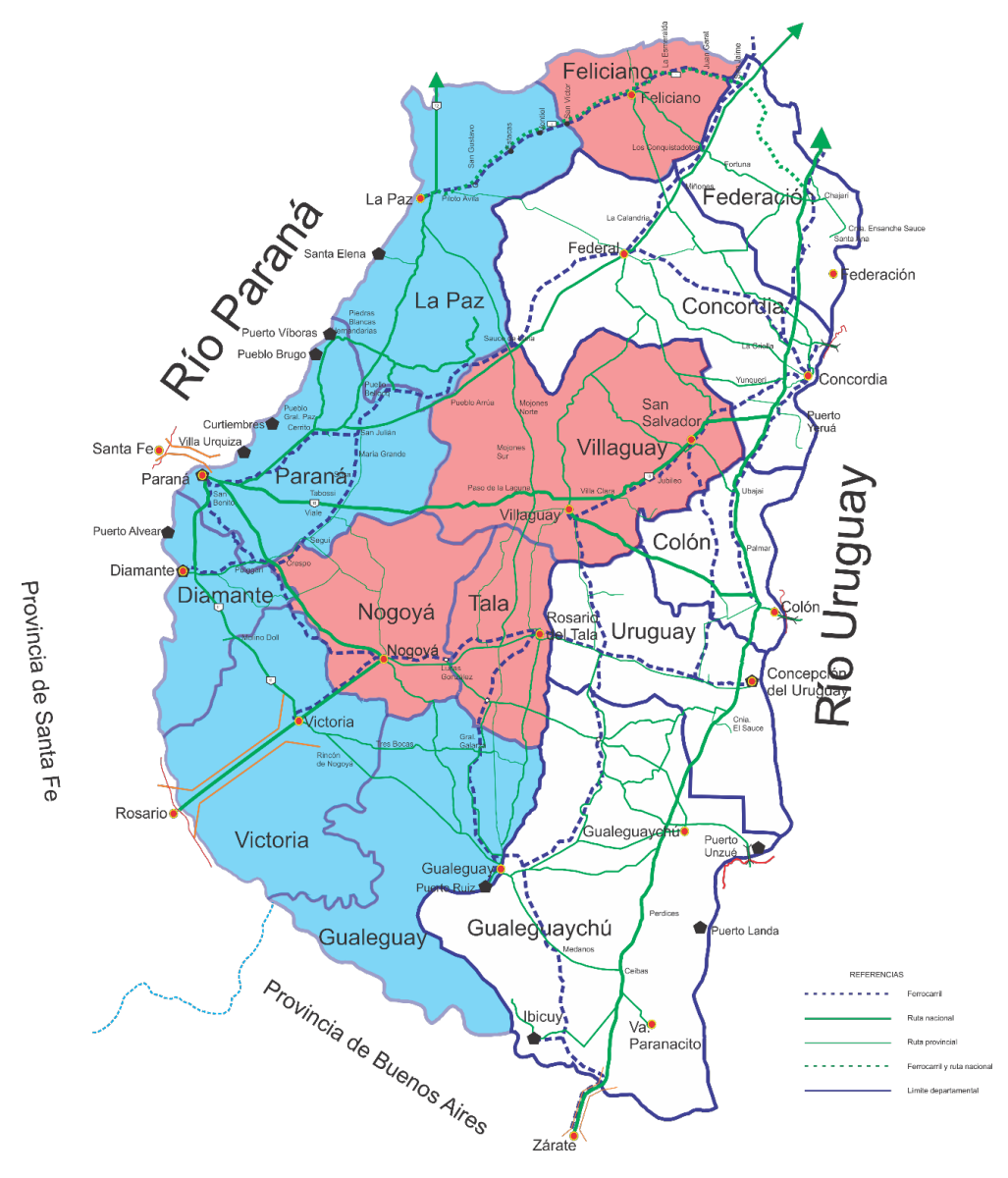

Como puede verse en el mapa 6, el tendido ferroviario ya había alcanzado casi su máxima extensión y al Ramal transversal Paraná-Crespo-Nogoyá-Tala-Concepción del Uruguay se acoplaban los puertos de Diamante, Victoria, Puerto Ruiz y Constanza. La línea Villaguay-Constanza sumaba en su recorrido a Concordia, Concepción del Uruguay y Gualeguaychú. El ramal longitudinal Paraná-San Jaime, a su vez engarza los de La Paz y Paraná. En su trayecto Federal se acoplaba a los puertos de Concordia y en menor medida los de Paraná y La Paz. A su vez, salvo los departamentos centrales (Feliciano, Villaguay, Nogoyá y Tala), y en alguna medida Federación por no ser navegable el tramo de los Saltos Grandes, todos cuentan con al menos una terminal portuaria.

Hemos calculado la distancia media a ferrocarril y puerto de los principales establecimientos productivos por departamento, y podemos observar que los más favorecidos eran los de Feliciano, Uruguay y Concordia y los más desfavorecidos los de Nogoyá, Victoria y Villaguay. El resto se encuentra en torno a las distancias medias, que como vemos, salvo en el caso de las chachas $(2,2 \mathrm{~km})$ no presentan una diferencia media mayor a $1 \mathrm{~km}$ que en la de Buenos Aires. 
Tabla 9. Distancias medias al puerto o ferrocarril (km)

\begin{tabular}{|c|c|c|c|}
\hline Departamentos & Chacra & Mixta & Cría \\
\hline Colón & 9,1 & 9,3 & 9,2 \\
\hline Concordia & 8,3 & 7,8 & 9,5 \\
\hline Diamante & 9,3 & 10,3 & 11,4 \\
\hline Federación & 11,2 & 8,9 & 9,3 \\
\hline Gualeguay & 9,9 & 10,7 & 13,1 \\
\hline Gualeguaychú & 11,1 & 11,2 & 11,4 \\
\hline La Paz & 10,9 & 10,8 & 11,4 \\
\hline Nogoyá & 12,6 & 12,1 & 11,6 \\
\hline Paraná & 10,8 & 10,4 & 10,9 \\
\hline Tala & 8,2 & 9,9 & 8,6 \\
\hline Feliciano & 5,9 & 8,3 & 8,6 \\
\hline Uruguay & 8,6 & 8,0 & 7,7 \\
\hline Victoria & 13,4 & 13,3 & 14,0 \\
\hline Villaguay & 11,8 & 11,7 & 14,0 \\
\hline Total & 10,2 & 10,1 & 10,7 \\
\hline Buenos Aires & 8,00 & 9,5 & 9,8 \\
\hline
\end{tabular}

Fuente: Censo Nacional Agropecuario

Tabla 10. Destino de los productos agrícolas en 1937

\begin{tabular}{|c|c|}
\hline Destino & $\%$ \\
\hline Acopiadores & 46,7 \\
\hline Distintos compradores & 14,4 \\
\hline Productores que remiten directamente a puerto & 12,9 \\
\hline Otros compradores & 12,2 \\
\hline Cooperativas & 5,4 \\
\hline Exportadores & 2,0 \\
\hline Consignatarios & 1,9 \\
\hline Molinos & 1,6 \\
\hline Mercados & 1,6 \\
\hline Remates feria & 0,9 \\
\hline Frigoríficos & 0,1 \\
\hline
\end{tabular}

Fuente: Censo Nacional Agropecuario

Si consideramos que los productores en su inmensa mayoría $(46,7 \%)$ vendían su producción a acopiadores lo que implicaba llevarla al pie del puerto o de la estación (Ortiz, 1943) y que otro $12,9 \%$ lo remitía directamente a puerto (tabla 9), los productores entrerrianos no parecieran estar en condiciones mucho más desfavorables que los bonaerenses en infraestructura, si probablemente en tanto a tarifas. 


\section{Conclusiones}

El gobernador Etchevehere, pretendió hacer un "gobierno definitivamente agrario", en momentos en que el modelo de acumulación en Argentina había virado hacia la industria sustitutiva. Probablemente esa fue una decisión inoportuna que, implementada mediante ayudas en producto y económicas, marcaría el futuro de la provincia.

Los datos parecen matizar la afirmación Reula (1971, p. 141) acerca de que la ganadería es la principal actividad económica. En principio si asimilamos el monte natural y cultivado como una forma de producción agrícola (sembrar árboles para cosechar su madera o sus frutos lo es) y le sumamos la superficie dedicada a cultivos, el $60 \%$ de la superficie estaba dedicada a la agricultura. Sin embargo, si estimamos la superficie multiplicando los establecimientos por su tamaño medio, el área destinada a actividades ganaderas era el 53,8\%, y la dedicada a actividades agrícolas $46,2 \%$. Podemos decir además que las actividades agrícolas demandan mayor cantidad de fuerza laboral, son más proclives a la formación de hogares y al afincamiento de la población. Por otro lado, la caída del valor del kilo vivo del ganado, las inclemencias climáticas y plagas pueden haber suscitado la multiplicación de estancias mixtas. También puede ser la estructura productiva de la provincia la causante de la mayor emigración, aunque todavía no muy acentuada o el despoblamiento rural en la provincia.

Las exportaciones por puertos (recordemos que aún la provincia no estaba vinculada físicamente al continente) también muestra este matiz. Aunque falta la información de los ferry-boats que actuaban desde 1912 (Cusmai, 2014), la cercanía a Puerto Constanza de la zona cereal no nos obliga a pensar que se extraían por allí menos productos ganaderos que agrícolas.

El elemento común a Entre Ríos durante este período es la heterogeneidad. Si observamos la distribución a partir del uso del suelo, encontramos al sur y noreste eminentemente ganadero y una zona central volcada a la agricultura, pero con una importante presencia de la ganadería. A su vez, si observamos la producción agropecuaria, este mapa se transforma y el predominio de la ganadería se encuentra solo en el noroeste (La Paz y Feliciano con una importante participación de ganado ovino). La clave en este sentido la encontramos en el tipo de unidad agropecuaria dominante. El predominio de las chacras de entre 25 y 50 hectáreas y las estancias mixtas da cuenta de este paisaje diverso en cuanto a la producción y de su supervivencia en el tiempo.

Las unidades productivas agropecuarias durante el periodo analizado gozaban de una gran diversidad, es probable que la mayor parte de las estancias dedicadas a la ganadería contengan en su interior una parte de tierra cultivada y lo mismo sucede con las dedicadas mayoritariamente a la agricultura. Es decir, la estancia mixta crecía como forma de manejo de los campos ayudada por la legislación vigente, dado que la clave era el desarraigo de los arrendatarios agrícolas cada cierto tiempo para dedicar las parcelas a la ganadería.

Para continuar este estudio, sugerimos analizar la producción y las características de las unidades productivas a largo plazo, para determinar el impacto de la Industrialización por Sustitución de Importaciones. Además, consideramos que es necesario aumentar la escala de análisis a cada uno de los departamentos en busca de vasos comunicantes que permita la construcción conceptualizaciones de las unidades territoriales. Por último, el abordaje de las 
cifras de los productos exportados por los puertos nos permitiría insertar a la producción entrerriana en la economía argentina. En tal sentido, se podrían tener en cuenta la competencia entre sistemas de transporte, su infraestructura, su logística y sus cuadros tarifarios. Otra línea de investigación consistiría en profundizar en la diacronía estos procesos para intentar comprender y explicar el devenir de la economía entrerriana en el contexto nacional, es decir, la correlación entre procesos endógenos y exógenos nacionales e internacionales.

\section{Referencias}

Arce, F. (1979). Historia. Paraná. En Enciclopedia de Entre Ríos. Arozena Editores.

Barsky, O. y Gelman, J. (2009). Historia del agro argentino: Desde la conquista hasta comienzos del siglo XXI. Buenos Aires: Sudamericana.

Biasizo, R. (2015). Economía de Entre Ríos en el período de intervencionismo conservador, 19301945. Paraná: EDUNER.

CFI y Coprode (1967). Compilación estadística de la Provincia de Entre Ríos. Consejo Federal de Inversiones \& Consejo Provincial del Desarrollo. Buenos Aires: Ex Libris.

Cusmai, C. (2014). Aquellos Queridos Ferrys. Historia de los Ferrobarcos del rio Paraná. Zárate: Galatea Ediciones.

Garcia, C. F. y Mingo de Bevilacqua, G. (1998). Situación demográfica de la provincia de Entre Ríos. Buenos Aires: INDEC.

González B., H. (2014). La fábrica de las cifras oficiales del Estado argentino, 1869-1947. Bernal: Universidad Nacional de Quilmes.

Gravil, R. (1970). State Intervention in Argentina's Export Trade between the Wars. Latin American Studies, 2, 156-157.

INDEC. (2010). Censo Nacional de Población, Hogares y Viviendas 2010. Recuperado 7 de octubre de 2017, a partir de http://www.indec.gob.ar/censos_total_pais.asp?id_tema_1=2\&id_ tema_2=41\&id_tema_3 $=135 \& \mathrm{t}=3 \& \mathrm{~s}=6 \& \mathrm{c}=2010$

Lattes, A. E. (1974). Redistribución espacial y migraciones. En Z. Recchini de Lattes \& Alfredo E. Lattes (eds.), La población de Argentina (pp. 95-112). Buenos Aires.

Leyes, R. (2013). No culpes a la crisis: inversiones de capital, mecanización y desocupación en Entre Ríos, 1928-1946. En XIV Jornadas Interescuelas/Departamentos de Historia. Mendoza.

Mathieu, M., Rodríguez, L. y Lambruschini, V. (2017). Ajuste en épocas de crisis: el caso de la provincia de Entre Ríos durante la Gran Depresión. Realidad Económica, 306, 77-103.

Ministerio de Agricultura. (1940a). Economía Rural 1937. En Censo Nacional Agropecuario. Buenos Aires: Guillermo Kraft Ltda.

Ministerio de Agricultura. (1940b). Economías rurales. En Censo Nacional Agropecuario. Buenos Aires: Guillermo Kraft Ltda.

Miro, C. (2000). Transición demográfica y envejecimiento demográfico. Papeles de Población No. 35 CIEAP/UAEM.

Ortiz, R. (1943). Valor económico de los puertos argentinos. Buenos Aires: Losada. 
Palacio, J. M. (2002). La estancia mixta y el arrendamiento agrícola: algunas hipótesis sobre su evolución histórica en la región pampeana, 1880-1945. Boletín del Instituto de Historia Argentina y Americana Dr. Emilio Ravignani, 25, 37-87.

Provincia de Entre Ríos. (1937). Síntesis estadística. Paraná: Ministerio de Economía.

Reula, F. (1971). Historia de Entre Ríos. Santa Fe: Castelleví.

Román, C. (2016). El proceso de fundación de villas como política del imperio español en la frontera oriental de América del sur. San Antonio de Gualeguay, Concepción del Uruguay y San José de Gualeguaychú. Entre Ríos, segunda mitad del siglo XVIII. Tesis de Maestría UNMdP.

Senado y Cámara de Diputados de la Nación argentina. (1932). Ley 11.627, sobre arrendamientos rurales. Recuperado 30 de septiembre de 2017, a partir de http://servicios.infoleg.gob. ar/infoleglnternet/anexos/175000-179999/178576/norma.htm 


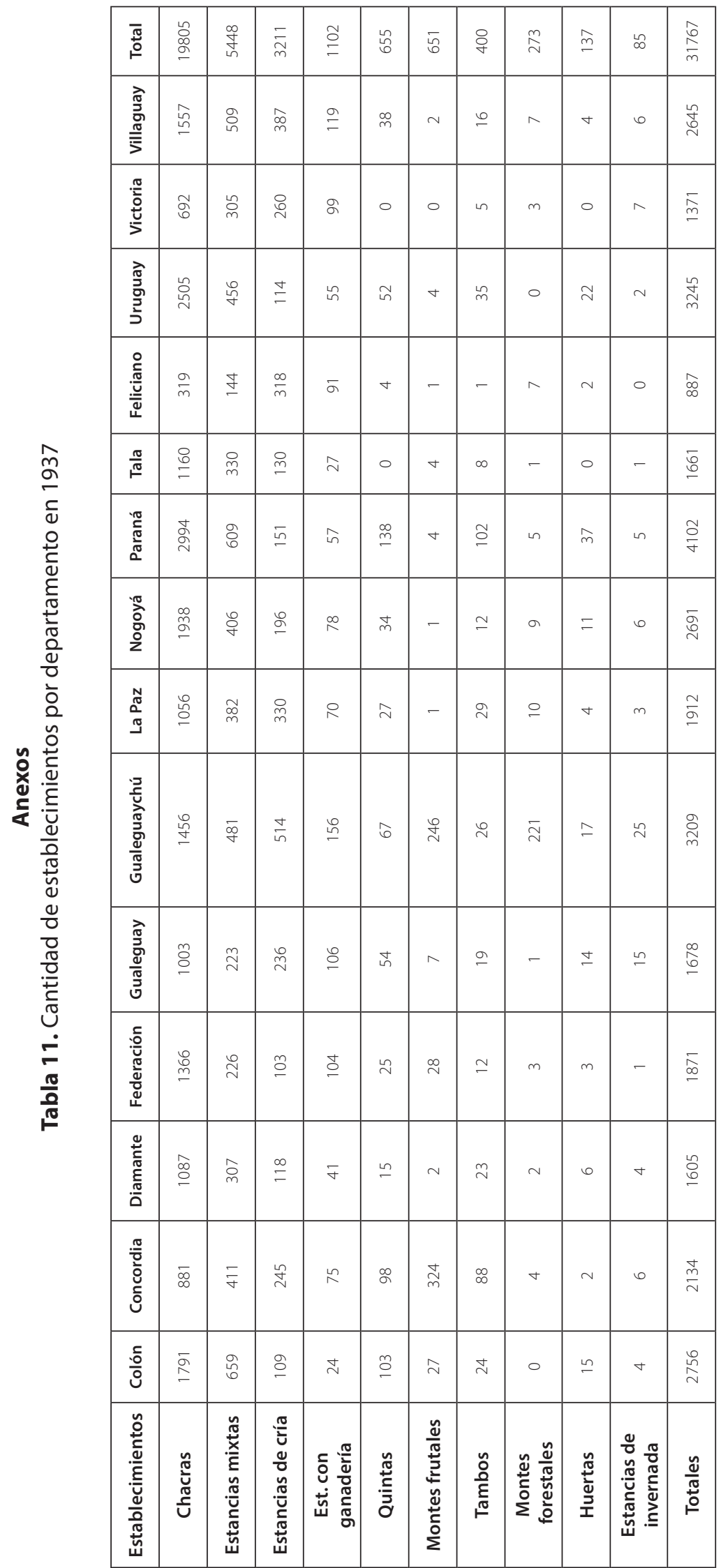




\begin{tabular}{|c|c|c|c|c|c|c|c|c|c|c|c|}
\hline 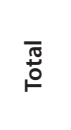 & 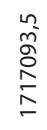 & 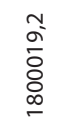 & $\begin{array}{l}\bar{m} \\
\stackrel{0}{0} \\
\stackrel{0}{\sigma}\end{array}$ & 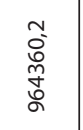 & 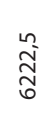 & $\begin{array}{l}\stackrel{n}{N} \\
\stackrel{0}{N} \\
\stackrel{N}{N}\end{array}$ & 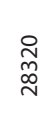 & $\begin{array}{l}\hat{N} \\
\hat{0} \\
\dddot{\sigma}\end{array}$ & 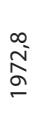 & $\begin{array}{l}m \\
\hat{心} \\
\stackrel{\circ}{\wedge}\end{array}$ & $\begin{array}{l}n \\
\stackrel{n}{0} \\
\stackrel{0}{N} \\
\substack{\infty \\
n}\end{array}$ \\
\hline 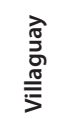 & $\begin{array}{l}a \\
\text { - } \\
\text { dे } \\
\text { m. }\end{array}$ & $\begin{array}{l}\stackrel{0}{\infty} \\
\stackrel{\infty}{\infty} \\
\stackrel{\infty}{0}\end{array}$ & $\begin{array}{l}\hat{i} \\
\frac{m}{q} \\
\bar{q}\end{array}$ & 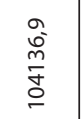 & $\overline{\tilde{D}}$ & $\begin{array}{l}0 \\
\text { đే }\end{array}$ & $\stackrel{\substack{i \\
m}}{=}$ & $\begin{array}{c}m \\
\stackrel{n}{E} \\
\equiv\end{array}$ & $\stackrel{0}{i n}$ & $\begin{array}{l}\infty \\
\infty \\
\infty \\
N_{n}^{\infty}\end{array}$ & $\begin{array}{l}n \\
\text { ò } \\
\text { hñ } \\
\text { hn }\end{array}$ \\
\hline 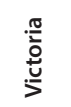 & 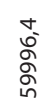 & 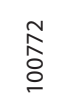 & $\frac{\text { d }}{\dot{f}}$ & \begin{tabular}{l} 
वे \\
\multirow{0}{0}{} \\
$\stackrel{0}{0}$ \\
$\infty$
\end{tabular} & ○ & 0 & 岕 & $\begin{array}{l}\hat{\sigma} \\
\hat{\sigma}\end{array}$ & 0 & 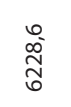 & $\begin{array}{l}\stackrel{N}{o} \\
\stackrel{\infty}{\infty} \\
\stackrel{\infty}{m}\end{array}$ \\
\hline $\begin{array}{l}\text { à } \\
\frac{5}{3} \\
\frac{3}{5}\end{array}$ & $\begin{array}{l}\stackrel{L^{n}}{\infty} \\
\stackrel{\infty}{\infty} \\
\stackrel{\infty}{N}\end{array}$ & $\begin{array}{l}\stackrel{+}{\vdots} \\
\text { o } \\
\stackrel{0}{0} \\
\end{array}$ & $\begin{array}{l}\stackrel{\sigma}{o} \\
\stackrel{+}{\sigma}\end{array}$ & 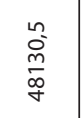 & 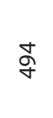 & ָ̃ & $\stackrel{\infty}{\stackrel{\infty}{\sim}}$ & ○ & $\begin{array}{l}\infty \\
\vdots \\
\vdots \\
m\end{array}$ & $\begin{array}{l}0 \\
\stackrel{0}{2} \\
\therefore\end{array}$ & 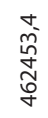 \\
\hline 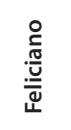 & 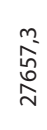 & $\begin{array}{l}\stackrel{0}{\hat{n}} \\
\stackrel{f}{f}\end{array}$ & $\begin{array}{l}\stackrel{\infty}{+} \\
\stackrel{+}{n} \\
=\end{array}$ & $\begin{array}{l}\bar{c} \\
\text { हूँ } \\
\text { ঃ }\end{array}$ & $\stackrel{\infty}{m}$ & $\underset{\sim}{\stackrel{m}{N}}$ & $\stackrel{\infty}{\stackrel{\infty}{R}}$ & $\underset{m}{a}$ & $\stackrel{\infty}{\infty^{\infty}}$ & $\circ$ & 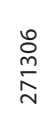 \\
\hline$\frac{\pi}{\sigma}$ & 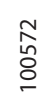 & $\begin{array}{l}\text { Õ } \\
\text { ò }\end{array}$ & $\begin{array}{l}\frac{m}{0} \\
\stackrel{5}{f}\end{array}$ & 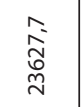 & $\circ$ & $\begin{array}{l}\text { ָे } \\
\text { }\end{array}$ & $\begin{array}{l}\text { to } \\
\text { ¿ } \\
\text { in }\end{array}$ & $\begin{array}{l}\text { مે } \\
\text { مे }\end{array}$ & 0 & $\begin{array}{l}\infty \\
\infty \\
\infty \\
\infty\end{array}$ & $\begin{array}{l}\text { O } \\
\text { ڤn } \\
\text { o } \\
\text { N }\end{array}$ \\
\hline $\begin{array}{l}\frac{\pi}{\pi} \\
\frac{\pi}{0} \\
\frac{\pi}{0} \\
0\end{array}$ & 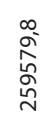 & $\begin{array}{l}\stackrel{0}{m} \\
\stackrel{N}{N} \\
\stackrel{N}{N}\end{array}$ & $\begin{array}{l}\bar{N} \\
\text { ô } \\
\text { in }\end{array}$ & $\begin{array}{l}\hat{0} \\
\infty \\
\infty \\
o \\
\sigma\end{array}$ & $\bar{m}$ & $\begin{array}{l}\text { ָे } \\
\text { ָे }\end{array}$ & 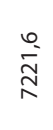 & $\begin{array}{l}\stackrel{n}{2} \\
\text { న }\end{array}$ & $\begin{array}{l}\infty \\
\stackrel{N}{N} \\
\text { ñ. }\end{array}$ & $\underset{j}{g}$ & \begin{tabular}{l}
$m$ \\
\multirow{2}{\alpha}{} \\
$\hat{\alpha}$ \\
in
\end{tabular} \\
\hline $\begin{array}{l}\text { 荡 } \\
\text { o } \\
\text { o }\end{array}$ & $\begin{array}{l}0 \\
\stackrel{0}{I} \\
\stackrel{0}{\infty} \\
\stackrel{0}{\sigma}\end{array}$ & 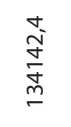 & $\begin{array}{l}\stackrel{0}{-} \\
\text { مे } \\
\end{array}$ & $\underset{\substack{n \\
0 \\
0}}{\stackrel{\infty}{0}}$ & $\stackrel{m}{m}$ & 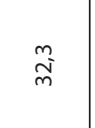 & $\begin{array}{l}\stackrel{0}{\circ} \\
\stackrel{\infty}{\infty}\end{array}$ & 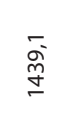 & $\begin{array}{l}\stackrel{+}{\infty} \\
\stackrel{n}{n}\end{array}$ & $\begin{array}{l}\infty \\
\infty \\
\infty \\
N \\
n\end{array}$ & $\begin{array}{l}\stackrel{0}{0} \\
\hat{N} \\
\hat{N} \\
\vdots\end{array}$ \\
\hline $\begin{array}{c}\pi \\
\frac{\pi}{0} \\
\end{array}$ & $\begin{array}{l}n ̃ \\
\text { ผn } \\
\text { ผn } \\
\sigma\end{array}$ & 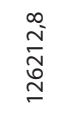 & $\begin{array}{l}m \\
\stackrel{o}{\sigma} \\
=\end{array}$ & 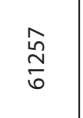 & 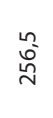 & $\stackrel{m}{\tilde{m}}$ & 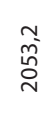 & مે & $\stackrel{0}{\text { in }}$ & \begin{tabular}{l}
\multirow{2}{\circ}{} \\
Oे \\
N
\end{tabular} & $\begin{array}{l}0 \\
\infty \\
\tilde{n} \\
\stackrel{+}{y}\end{array}$ \\
\hline 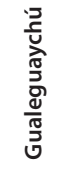 & 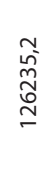 & 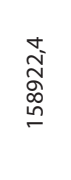 & $\begin{array}{l}\stackrel{t}{\sigma} \\
\frac{\sigma}{\sigma} \\
\stackrel{0}{\sigma}\end{array}$ & 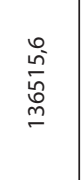 & $\begin{array}{l}\text { గn } \\
\text { Oे } \\
0\end{array}$ & \begin{tabular}{l}
$\infty$ \\
ơ \\
\multirow{2}{\alpha}{}
\end{tabular} & 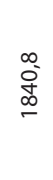 & 商 & $\underset{\underset{\sim}{\mathbb{J}}}{\stackrel{\infty}{*}}$ & 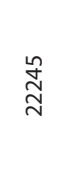 & \begin{tabular}{l}
0 \\
\multirow{3}{*}{} \\
$o$ \\
0 \\
6
\end{tabular} \\
\hline $\begin{array}{l}\text { बे } \\
\frac{0}{5} \\
\frac{0}{0} \\
\frac{0}{5}\end{array}$ & 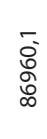 & $\begin{array}{l}\text { Na } \\
\text { ôे } \\
\text { ñ }\end{array}$ & 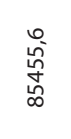 & $\begin{array}{l}\stackrel{0}{\circ} \\
\stackrel{0}{\text { aे }} \\
\text { a }\end{array}$ & $\frac{m}{i n}$ & $\begin{array}{l}\overline{0} \\
\bar{N}\end{array}$ & 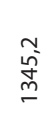 & $\begin{array}{l}\text { مे } \\
\text { مे }\end{array}$ & $\begin{array}{l}0 \\
\stackrel{\sim}{N}\end{array}$ & $\underset{\stackrel{\text { f }}{\sim}}{\sim}$ & 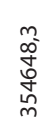 \\
\hline 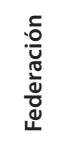 & $\begin{array}{l}\mathfrak{N} \\
\underset{N}{\tilde{Y}} \\
\infty \\
=\end{array}$ & \begin{tabular}{l}
\multirow{2}{0}{} \\
$\stackrel{0}{N}$ \\
\multirow{1}{N}{}
\end{tabular} & 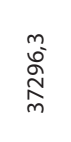 & $\begin{array}{l}\stackrel{5}{\circ} \\
\vdots \\
\vdots\end{array}$ & $\stackrel{n}{\stackrel{n}{N}}$ & $\begin{array}{l}+ \\
\stackrel{+}{\circ}\end{array}$ & $\begin{array}{l}\stackrel{\circ}{\circ} \\
\stackrel{\infty}{\infty}\end{array}$ & $\begin{array}{l}\hat{\sigma} \\
\hat{f}\end{array}$ & $\stackrel{\sim}{\tilde{q}}$ & $\begin{array}{l}\infty \\
\stackrel{-}{-} \\
\infty \\
\infty\end{array}$ & $\begin{array}{l}\stackrel{n}{n} \\
\stackrel{m}{o} \\
\stackrel{o}{d} \\
\stackrel{m}{m}\end{array}$ \\
\hline 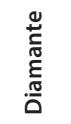 & 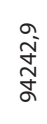 & $\begin{array}{l}\stackrel{\infty}{ } \\
\stackrel{N}{\tilde{y}} \\
\stackrel{\sigma}{0}\end{array}$ & $\stackrel{\infty}{\stackrel{\infty}{\sim}}$ & $\begin{array}{l}\bar{o} \\
\infty \\
\infty \\
m \\
n\end{array}$ & $\begin{array}{l}\stackrel{n}{\sim} \\
\underset{\sim}{\tau}\end{array}$ & $\begin{array}{l}\circ \\
\text { ষ் }\end{array}$ & $\begin{array}{l}\stackrel{+}{\infty} \\
\underset{\sigma}{\sigma}\end{array}$ & 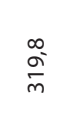 & ণ্ঠ & $\begin{array}{l}\text { مू } \\
\hat{n} \\
\text { no }\end{array}$ & 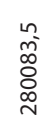 \\
\hline 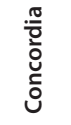 & 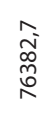 & 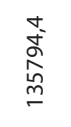 & $\underset{\substack{n \\
\infty}}{\stackrel{n}{\sim}}$ & 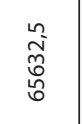 & $\bar{n}$ & 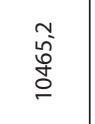 & 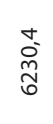 & $\begin{array}{l}0 \\
\text { Oे } \\
0\end{array}$ & $\stackrel{\infty}{\infty} \underset{\sim}{\sim}$ & $\begin{array}{l}\infty \\
\infty \\
\prod_{n}^{\infty} \\
n_{n}\end{array}$ & 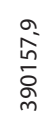 \\
\hline 흥 & 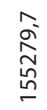 & $\begin{array}{c}\stackrel{0}{\infty} \\
\stackrel{N}{N} \\
\stackrel{N}{N}\end{array}$ & $\begin{array}{l}\text { ô } \\
\text { oे } \\
\text { ợ } \\
\text { mे }\end{array}$ & ì & $\begin{array}{l}\stackrel{n}{\infty} \\
\infty^{\infty} \\
\sigma\end{array}$ & $\underset{\infty}{\bar{N}}$ & \begin{tabular}{l}
\multirow{\sigma}{\sigma}{} \\
$\sigma$
\end{tabular} & 0 & $\stackrel{\circ}{\sim}$ & 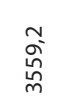 & $\begin{array}{l}0 \\
0 \\
0 \\
o \\
o ̛ j\end{array}$ \\
\hline 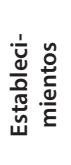 & 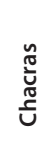 & 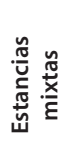 & 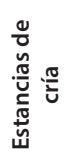 & 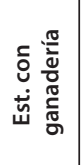 & 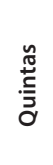 & 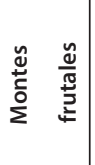 & $\begin{array}{l}\stackrel{\swarrow}{\circ} \\
\stackrel{\circ}{\xi} \\
\stackrel{\circ}{\sigma}\end{array}$ & 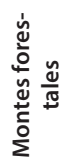 & 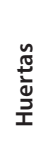 & 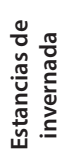 & $\begin{array}{l}\frac{\tilde{\omega}}{\pi} \\
\stackrel{0}{\circ}\end{array}$ \\
\hline
\end{tabular}


Tabla 13. Trigo

\begin{tabular}{|c|c|c|c|c|c|c|}
\hline Departamento & $\begin{array}{c}\text { Unidades } \\
\text { productivas }\end{array}$ & $\begin{array}{c}\text { Superficie } \\
\text { sembrada }\end{array}$ & Producción & $\%$ UP & $\%$ SS & $\%$ P \\
\hline Colón & 1589 & 20000 & 14280 & 11,3 & 5,4 & 6,2 \\
\hline Concordia & 528 & 8500 & 3500 & 3,8 & 2,3 & 1,5 \\
\hline Diamante & 852 & 26000 & 24200 & 6,1 & 7,1 & 10,5 \\
\hline Federación & 67 & 1000 & 210 & 0,5 & 0,3 & 0,1 \\
\hline Galeguay & 395 & 15000 & 10010 & 2,8 & 4,1 & 4,3 \\
\hline Gualeguaychú & 1250 & 58000 & 42500 & 8,9 & 15,7 & 18,5 \\
\hline La Paz & 726 & 17000 & 9800 & 5,2 & 4,6 & 4,3 \\
\hline Nogoyá & 1524 & 44000 & 26000 & 10,8 & 11,9 & 11,3 \\
\hline Paraná & 2572 & 79000 & 42600 & 18,3 & 21,4 & 18,5 \\
\hline Tala & 813 & 24000 & 15330 & 5,8 & 6,5 & 6,7 \\
\hline Feliciano & 28 & 400 & 82 & 0,2 & 0,1 & 0,0 \\
\hline Uruguay & 2064 & 39000 & 26400 & 14,7 & 10,6 & 11,5 \\
\hline Victoria & 266 & 7500 & 3680 & 1,9 & 2,0 & 1,6 \\
\hline Villaguay & 1383 & 29000 & 11560 & 9,8 & 7,9 & 5,0 \\
\hline Total & 14057 & 368400 & 230152 & 100,0 & 100,0 & 100,0 \\
\hline
\end{tabular}

Fuente: Censo Nacional Agropecuario

Tabla 14. Lino

\begin{tabular}{|c|c|c|c|c|c|c|}
\hline Departamento & $\begin{array}{c}\text { Unidades } \\
\text { productivas }\end{array}$ & $\begin{array}{c}\text { Superficie } \\
\text { sembrada }\end{array}$ & Producción & $\%$ UP & $\%$ SS & $\%$ P \\
\hline Colón & 1860 & 30000 & 13920 & 10,0 & 4,3 & 5,0 \\
\hline Concordia & 796 & 20000 & 8100 & 4,3 & 2,9 & 2,9 \\
\hline Diamante & 1107 & 48000 & 25840 & 5,9 & 6,9 & 9,3 \\
\hline Federación & 733 & 7000 & 2580 & 3,9 & 1,0 & 0,9 \\
\hline Galeguay & 775 & 55000 & 27950 & 4,2 & 7,9 & 10,0 \\
\hline Gualeguaychú & 1451 & 78000 & 33600 & 7,8 & 11,2 & 12,1 \\
\hline La Paz & 1198 & 50000 & 19200 & 6,4 & 7,2 & 6,9 \\
\hline Nogoyá & 1910 & 82000 & 31960 & 10,2 & 11,7 & 11,5 \\
\hline Paraná & 2781 & 107000 & 37260 & 14,9 & 15,3 & 13,4 \\
\hline Tala & 1045 & 44000 & 18240 & 5,6 & 6,3 & 6,5 \\
\hline Feliciano & 175 & 2200 & 540 & 0,9 & 0,3 & 0,2 \\
\hline Uruguay & 2453 & 68000 & 26520 & 13,2 & 9,7 & 9,5 \\
\hline Victoria & 745 & 60000 & 21660 & 4,0 & 8,6 & 7,8 \\
\hline Villaguay & 1623 & 48000 & 11180 & 8,7 & 6,9 & 4,0 \\
\hline Total & 18652 & 699200 & 278550 & 100,0 & 100,0 & 100,0 \\
\hline
\end{tabular}

Fuente: Censo Nacional Agropecuario 
Tabla 15. Maíz

\begin{tabular}{|c|c|c|c|c|c|c|}
\hline Departamento & $\begin{array}{c}\text { Unidades } \\
\text { productivas }\end{array}$ & $\begin{array}{c}\text { Superficie } \\
\text { sembrada }\end{array}$ & Producción & $\%$ UP & $\%$ SS & $\%$ P \\
\hline Colón & 2284 & 26000 & 23460 & 11,1 & 8,2 & 9,9 \\
\hline Concordia & 1251 & 18000 & 7930 & 6,1 & 5,6 & 3,3 \\
\hline Diamante & 973 & 16000 & 13000 & 4,7 & 5,0 & 5,5 \\
\hline Federación & 1462 & 14000 & 9360 & 7,1 & 4,4 & 3,9 \\
\hline Galeguay & 831 & 12000 & 8370 & 4,0 & 3,8 & 3,5 \\
\hline Gualeguaychú & 1288 & 25000 & 19320 & 6,3 & 7,8 & 8,1 \\
\hline La Paz & 1091 & 15000 & 7592 & 5,3 & 4,7 & 3,2 \\
\hline Nogoyá & 1688 & 31000 & 18900 & 8,2 & 9,7 & 8,0 \\
\hline Paraná & 2939 & 49000 & 43260 & 14,3 & 15,4 & 18,2 \\
\hline Tala & 1082 & 18500 & 11544 & 5,3 & 5,8 & 4,9 \\
\hline Feliciano & 600 & 4500 & 1620 & 2,9 & 1,4 & 0,7 \\
\hline Uruguay & 2528 & 43000 & 33840 & 12,3 & 13,5 & 14,2 \\
\hline Victoria & 554 & 14000 & 18460 & 2,7 & 4,4 & 7,8 \\
\hline Villaguay & 2019 & 33000 & 21000 & 9,8 & 10,3 & 8,8 \\
\hline Total & 20590 & 319000 & 237656 & 100,0 & 100,0 & 100,0 \\
\hline
\end{tabular}

Fuente: Censo Nacional Agropecuario 